\title{
THE PARADIGM OF MATN HADITH CRITICISM AND ITS TRANSFORMATION IN THE MODERN ERA
}

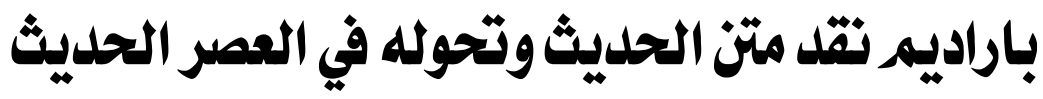

Darul Siswanto

Universitas Islam Negeri Sunan Kalijaga Yogyakarta, Indonesia

E-mail: dar.el.ula@gmail.com

\section{Abstract}

Hadiths or Prophetic traditions as primary sources after Quran in Islamic teachings are important to examine and criticize in terms of authenticity and contents. This research aims at discovering the paradigm of matn hadith criticism used by hadith scholars by looking at their methodology. It is also an attempt to answer some Orientalist opinions about classical hadith scholars who only focus on the criticism of sanad and ignore the matn criticism. Through the inductive method, it can be said that the paradigm believed by hadith scholars in matn critique is the law of contradiction where it is impossible for two authentic hadiths to oppose each other as well as it is impossible for sahih and daif hadiths to be different (ikhtilâf). Then this research also tries to discover the form of transformation of the matn hadith criticism in the modern era and that Islamic values are still very relevant in all places and times. This research also shows that there are two forms of transformation, namely internal and external transformation, both of which are driven and influenced by the development and progress of the modern era. 
الأحاديث النبوية كمصدر أولية بعد القرآن في التعاليم الإسلامية مهمة لاختبارها وانتقادها من حيث صحة صفاتها ومحتوياتها. ونقصد من هذا البحث الكشف عن باراديم نقد متن الحديث الذي يستخدمه علماء الحديث من خلال النظر في المنهجية التي يستخدمونها في تنفيذ نقد المتن.

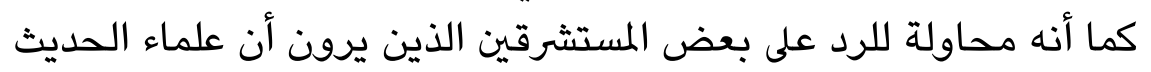
يركزون فقط على نقد الإسناد دون النقد على متن الحديث. ومن خلال

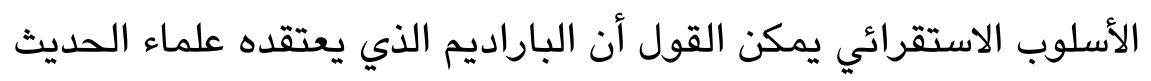

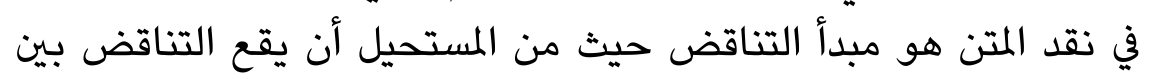
الأحاديث الصحيحة بعضها البعض، حيث من المستحيل أن يقال أن

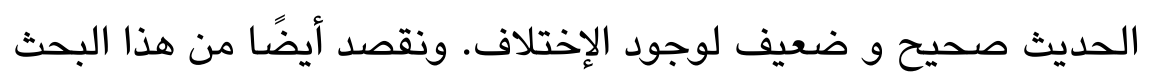
الكشف عن شكل تحول نقد متن الحديث في العصر الحديث، ليكون دليلا

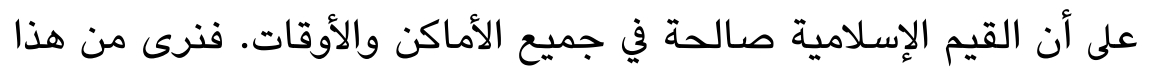
البحث أن هناك شكلين من أشكال التحول لنقد المتن في العصر الحديث الإني وهما التحول الداخلي والتحول الخارجي، وكلاهما مدفوع ومتأشثر بتطورالزمن وتقدمه.

Keywords: contradiction; matn hadith criticism; paradigm; transformation Received: March 10, 2020; Accepted: June 15, 2020

المقدمة

الحديث النبوي هو مصدر التعاليم الإسلامية بعد القرآن الكريم. ومع كون تاريخ الجمع والتدوين الطويل للأحاديث النبوية بكل الخلافات فيه، قام علماء الحديث بتصنيف الحديث وتفصيله بين القبول والرد لتجنب أي تحريف للحديث. وعملية هذا التصنيف من علماء الحديث كادت صارمة جدا، ولكن لا يصح القول بعد ذلك التصنيف بأن الدراسة والبحث في الحديث لم يعد ضروريا. بالإضافة إلى الى الى نقد سند الحديث النبوي كعملية تصنيف، فإن نقد المتن للحديث مهم أيضًا. إنه ليس إلا لإعطاء مزيد في تقوية الإسناد، بل كان البحث والنقد في المتن ذو أهمية 
كبيرة لأن نص الحديث كمصدر لدين الإسلام ضروري لشرح صفاته وشرح كيفية ارتباطه بالمصدر الأول الذي هو القرآن الكريم وعلاقته بمبادئ هذا لإن الدين الدين.

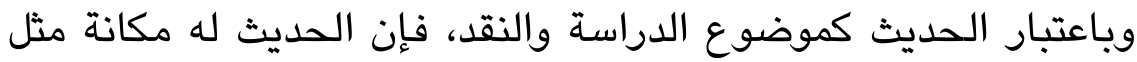

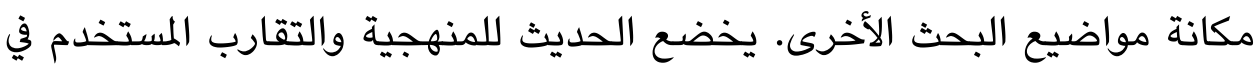

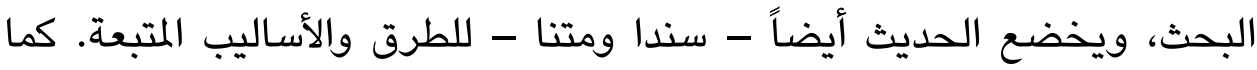

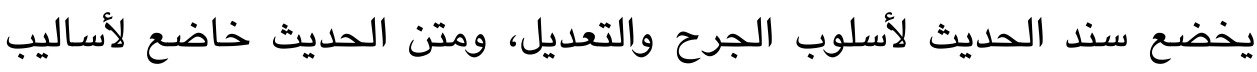

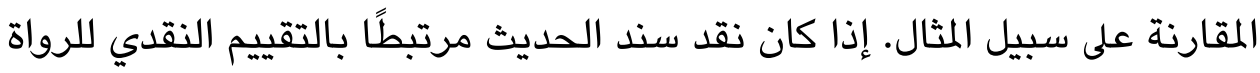

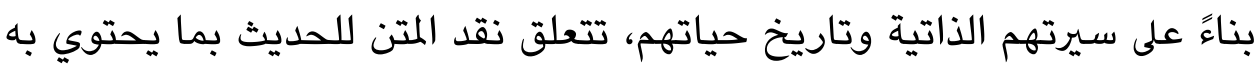
النص من التعالم الدينية ويالقواعد اللغوية فيه وبالأحاديث الأخرى ذاتية التات الصلة

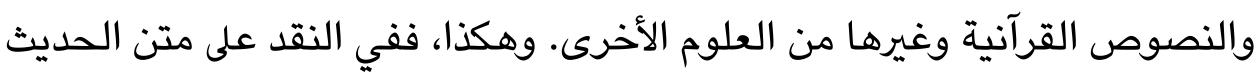

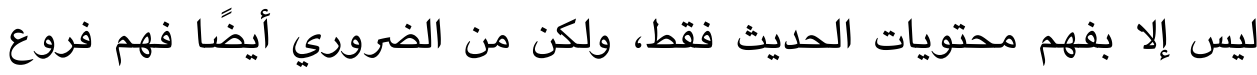

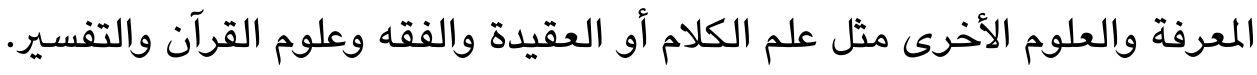

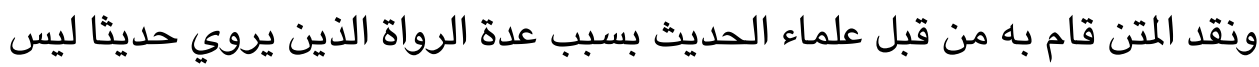

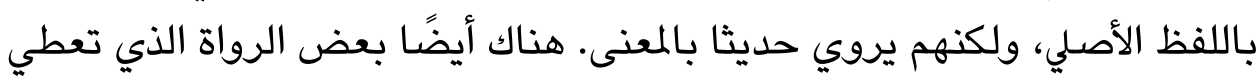
زيادة في اللفظ تفسيراً وبيانا منهم. الرواية بالمعنى كما ذكرنا، توجد العديد في تراث الفقهاء الذين يرون

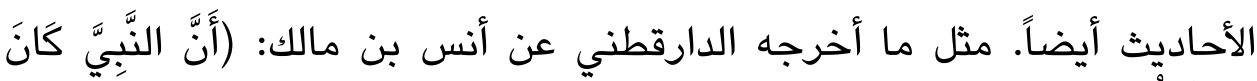

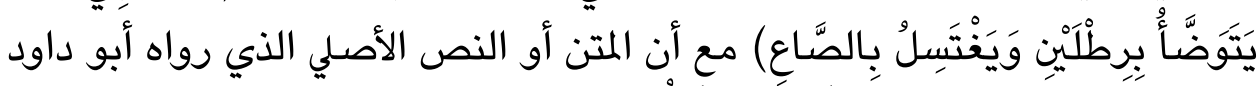

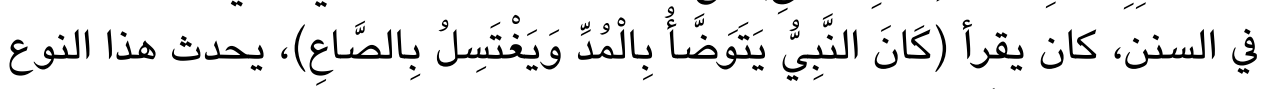

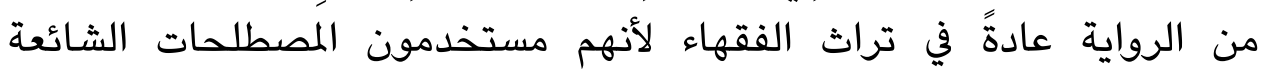
بالاستخدام من قبل الجماهر حولهم.

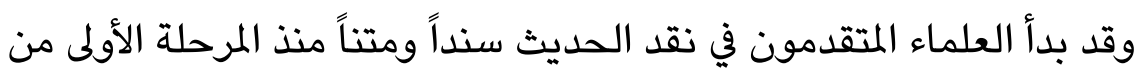
عصر التدوين للأحاديث النبوية. ومن مصادر مختلفة من مصنفاء المنفات التراث

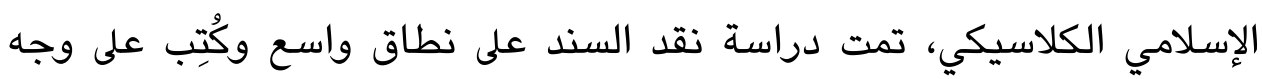

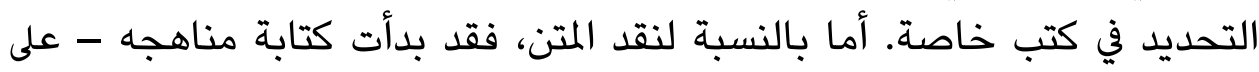

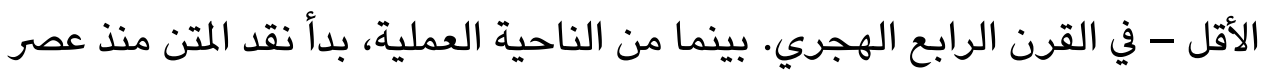


النبي صلى الله عليه وسلم. ومهما كان ذلك فإن الكتب التي تحتوي على نقد المتن ليست منظمة منهجية مثل الكتب التي تحتوي على نقد الإسناد.

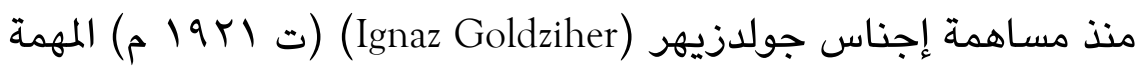
في دراسة الحديث، كان المفكر الغربي عموما يقبل إدعائه أن نقد الحديث في بداية الإسلام يرى الإسناد دون المتن من الأحاديث لمعرفة صحتها (Brown 2008, 182).

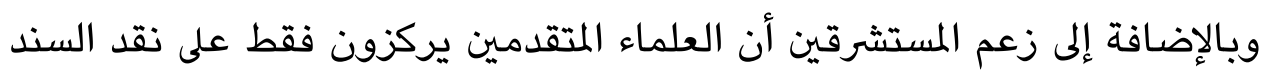

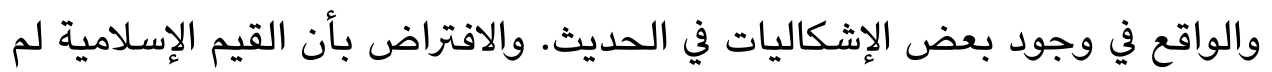
تعد ذات صلة وقابلة للتطبيق، والتي يتجلى أحدها في نقد متن الحديث هو أيضًا شيء يحتاج إلى الجواب. كيف يتم نقد متن الحديث ذو صلة في العصى العد الحديث

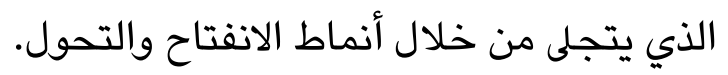
النقد المتني للأحاديث النبوية من حيث المنهجية لم تكن تتم كتابتها في في

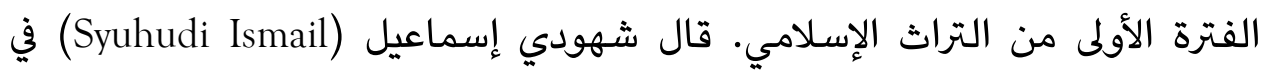

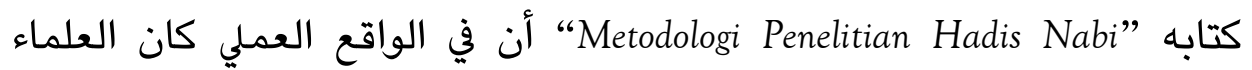

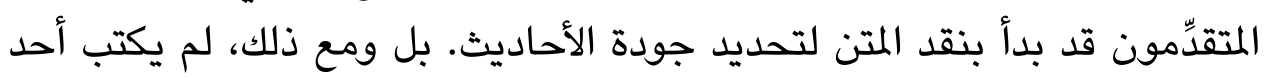

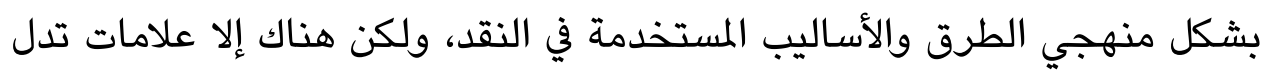
على إمكان استخدامها في النقد المتني. في إحدى نتيجة بحثه، أوضح شهودي أنه من الطبيعي أن يكون هناك انطباع بأن علماء الحديث يفضلون نقد سند الحديث بدلاً من نقد متن الحديث. ومع ذلك، لا يمكن الشك في جدية علماء الحديث في البحث عن متون الأحاديث

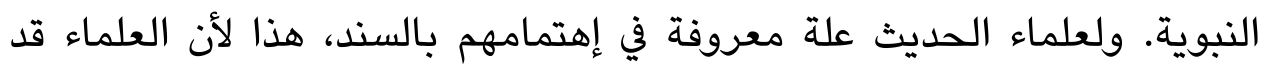

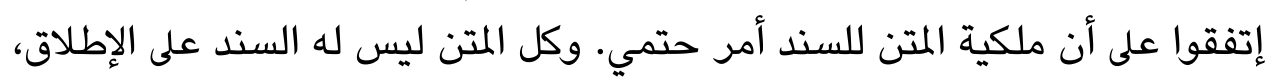

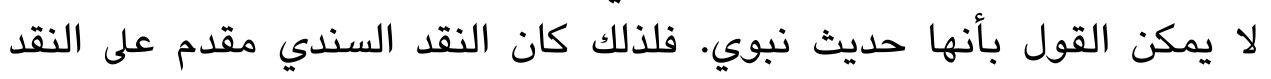

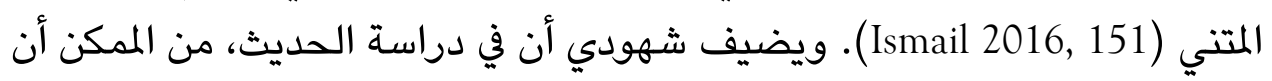

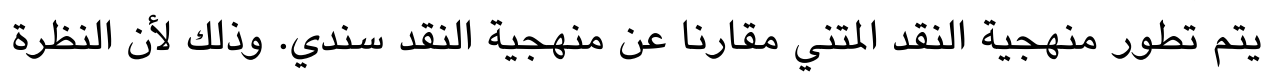

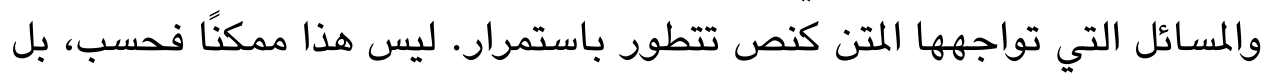

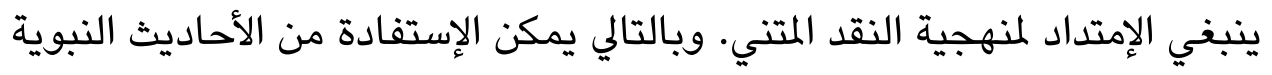


كواحد من مصادر التشريع والإرشاد عند المسلمين للإجابة على تحديات العصر .(Ismail 2016, 152)

"Eksistensi Kritik Matan " وقد إتفق مع ما بينه شهودي مقالة بعنوان (Amrullah "Masa Awal: Membaca Temuan dan Kontribusi Jonathan Brown (2016. تبين المقالة، بالإشارة إلى نتائج البحث عند براون من بعض كتب الحديث الإيث

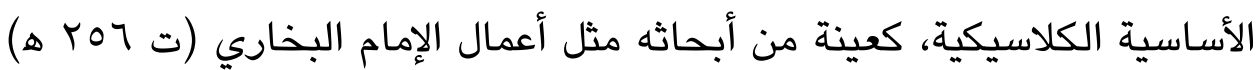

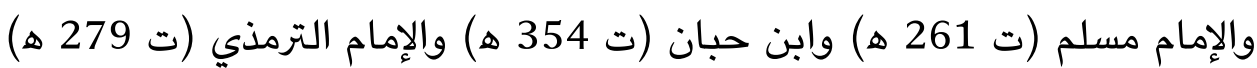

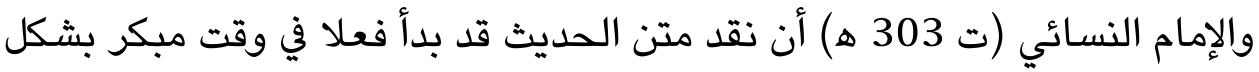

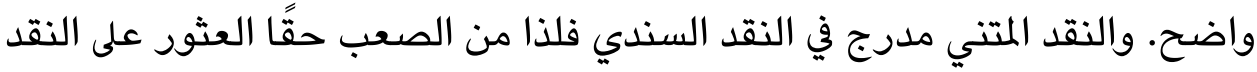
المتني حتى لو تم العثور عليها فهي ضئيلة للغاية. ويؤكد براون أن السبب في قلة النقد على المتئن فئل في الأيام الأولى لأن علماء

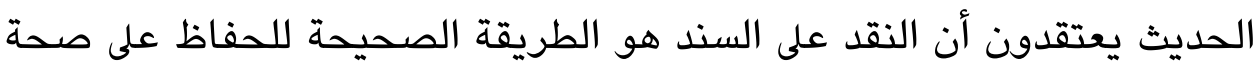

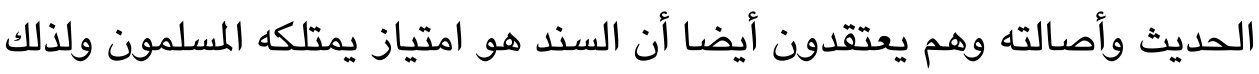

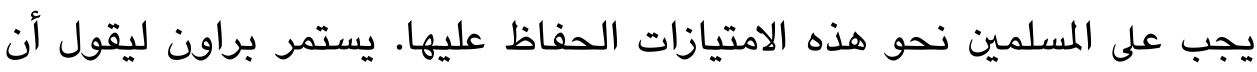
معتقدات الأحاديث تتعارض مع رأي العقلانيين العمليين (practical rationalist)

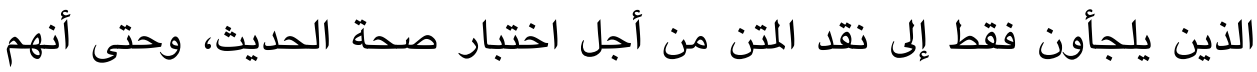

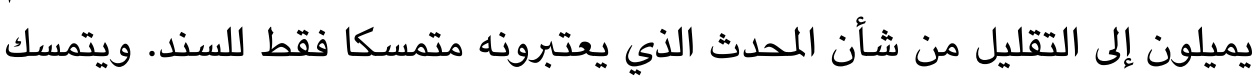

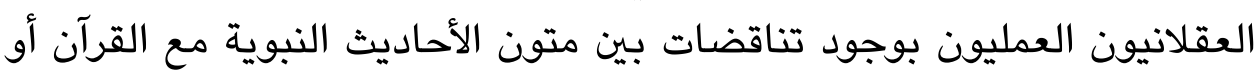

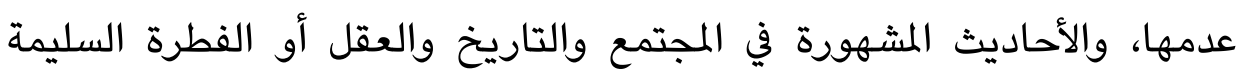
.(Brown 2008, 183)

وفي مقالة أخرى بعنوان" Paradigma Ulama Dalam Menentukan Kualitas .(Mujibatun 2014)"Hadis dan Implikasinya Dalam Kehidupan Umat Islam توضح المقالة أن علماء الحديث بباراديمهم في تحديد نوعية الحديث لهم رموز ومفهوم يختلف بعضهم بعضا. وهناك من العلماء المتشددون والمتوسطون والمتسهلون بل منهم المتعنتون. فالمفاهيم والأنماط المختلفة لدى هؤلاء العاء العلماء قد المداء

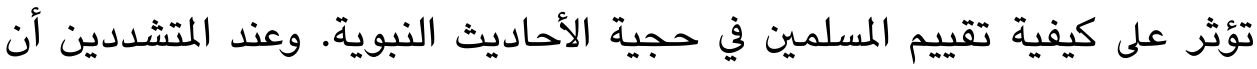


الأحاديث التي لا تستوفي شروط الصحة على الإطلاق لا يمكن أن تستخدم كدليل

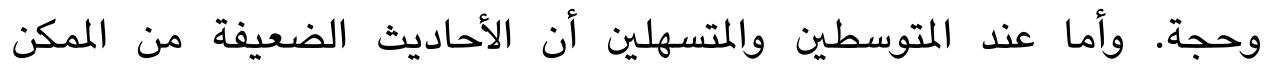
استخدامها كدليل في المسائل خارج المسائل الإصولية الإعتقادية على سبيل المثال.

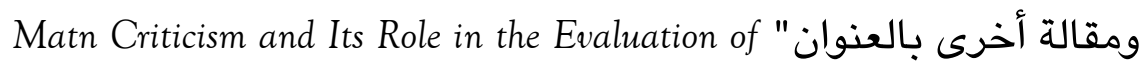
"Hadith Authenticity الأكاديميون الحديثون إلى علم الحديث الذي يعتبره مركز على نقد السند فقط،

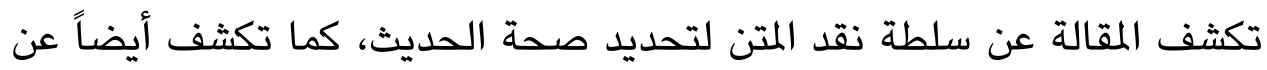
الأساليب والمناهج المستخدمة سواء كانت تتضمن أو لا تتضمن في الطرق التقليدية والمعايير المطبقة لعلم الحديث.

Kritik Matan Hadis Studi Komparatif antara " ومقالة أخرى بعنوان Muhsin 2017)" Sarjana Muslim dan Sarjana Barat الأساليب والطريقة المستخدمة من قبل علماء المسلمين يعني أسلوب المقارنة وأسلوب المعارضة أكثر فعالية ودقة من طريقة الروابط المشتركة (common link) المستخدمة من قبل العلماء الغربيين في عملية النقد على متون الحديث. والمقالة Methodology of Hadith Content Criticism: A Study " الأخرى عن نقد المتن بالعنوان Tangngareng 2016)" of the Thought of Salah al-Din bin Ahmad al-Adlabi نص المقالة على الأفكار التي طورها الإدلبي فيما يتعلق بنقد متن الحديث مع بيان

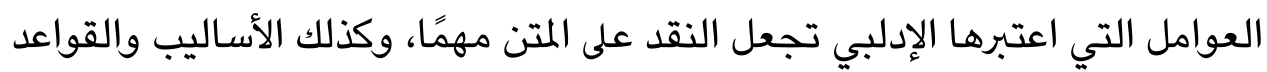
التي يستخدمها الإدلبي في نقد متن الحديث.

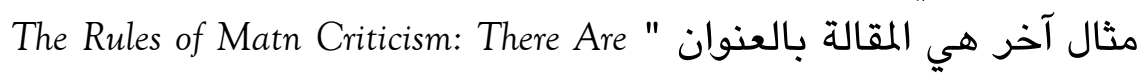
No Rules

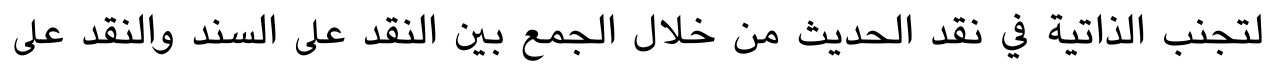
المعنى الوارد في المتن، بدلا من ذلك جعل تشويقا داخليا في هذا المذهب. وأن للعلماء

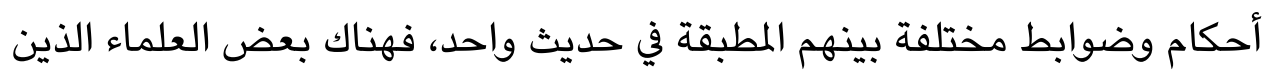

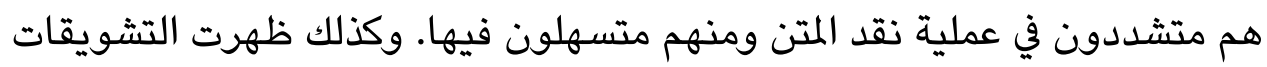
والتوترات الناشئة عن ذاتية نقد المتن في العصر الحديث، عندما أصبح العلم 
الحديث والأعراف الاجتماعية الحديثة تحديًا لم يكن في زمن مسبوق (ما قبل الحداثة). (- ماثل

من مراجعة الأبحاث والمقالات التي أجراها المؤلف فيما ذكرناها سابقاً،

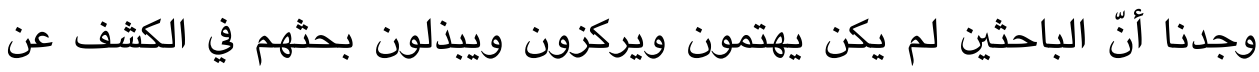
الباراديم المستخدمة عند علماء الحديث في عملية نقد متن الحديث ونديث.

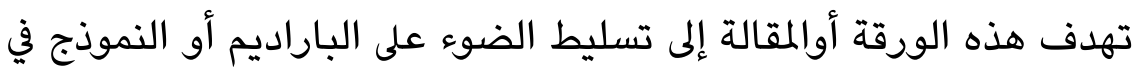
نقد متن الحديث، وكيفية الطريقة المنهجية فيه منذ العصر الإسلامي القديم،

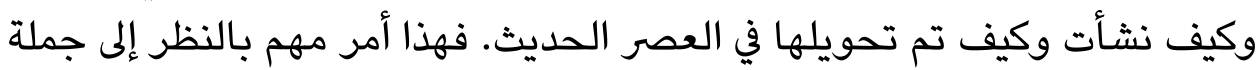

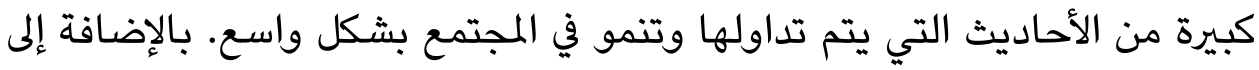

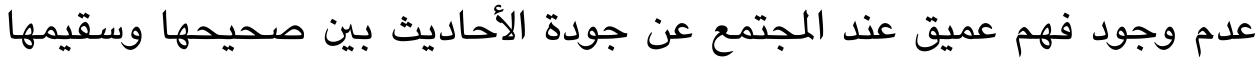

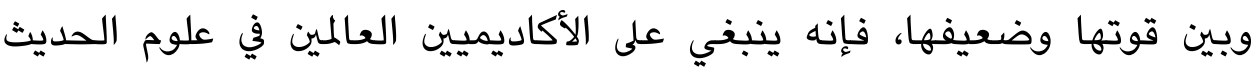

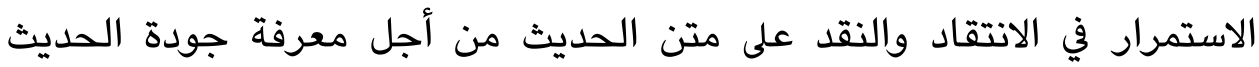

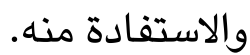

وليكون هذا البحث مركزاً تركيزا وفعالية، يستخدم الكاتب الباحث طريقة

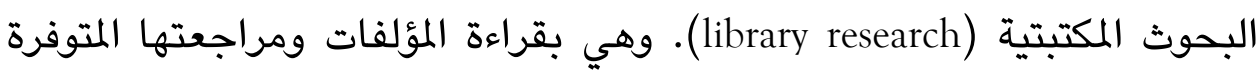
المتعلقة بدراسة الحديث عامة ونقد المتن بشكل خاص. أما النظر والنهج الذي الني يستخدمه المؤلف هو النهج التحليلي الوصفي (descriptive analytical) من خلال التهال

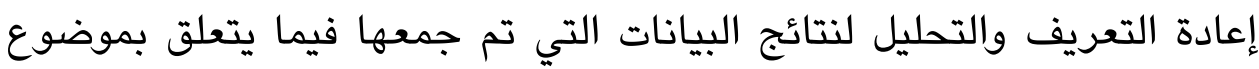

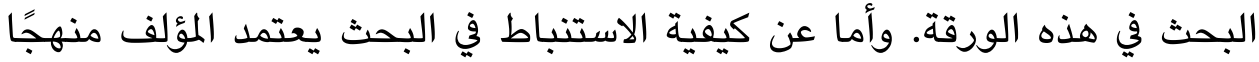

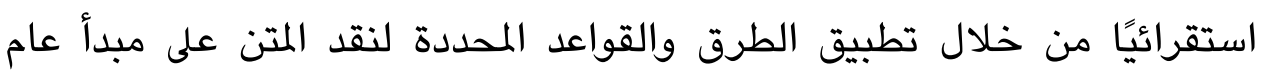
كإطار فكري في النقد على متن الحديث.

\section{علم الحديث وتاريخ نشأته}

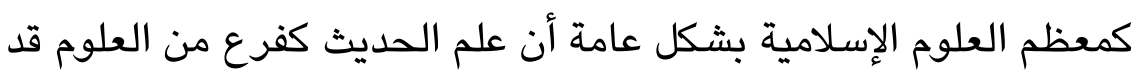

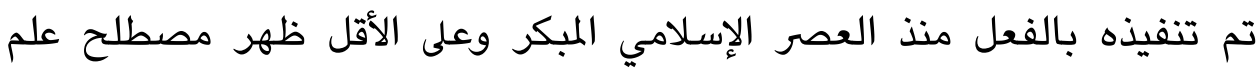

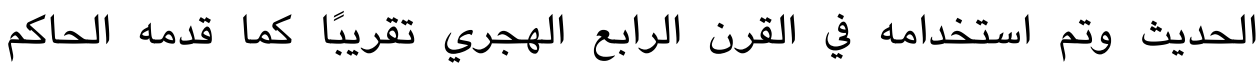


النيسابوري (ت 0 •ع هـ) في كتابه "معرفة علوم الحديث". إن علماء الحديث الإيث

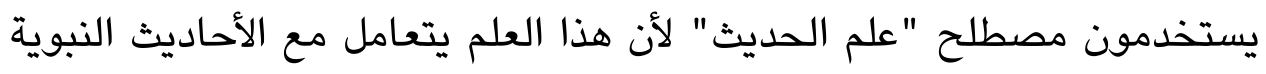

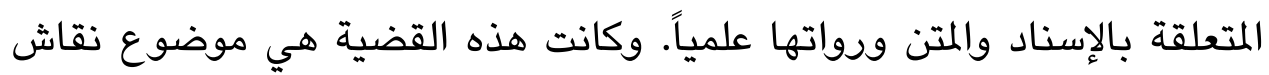

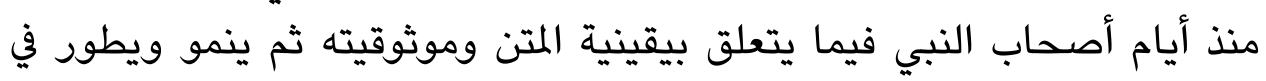
عصر التابعين. وفي مرحلة لاحقة تطور هذا العلم في قضية الإسناد وتسلسلها

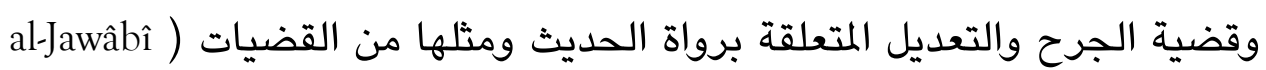
.). (1991, 72

ويمكن بعد ذلك وضع علامة على تطور علم الحديث، خاصة عندما تبدأ

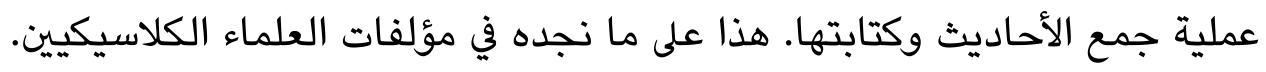

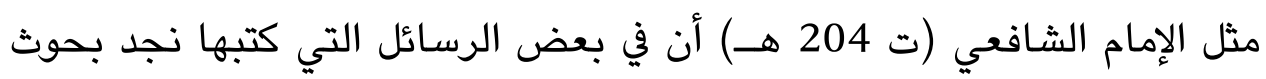

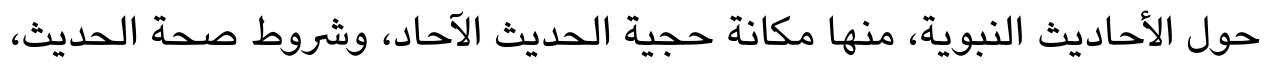

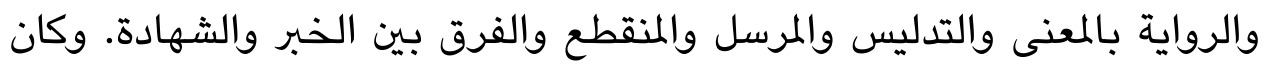

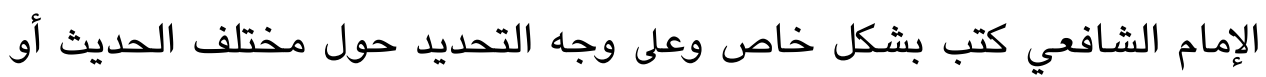
الأحاديث المختلف في ملحق كتابه "الأم".

ومثال آخر هو الإمام مسلم (ت الأمابه"

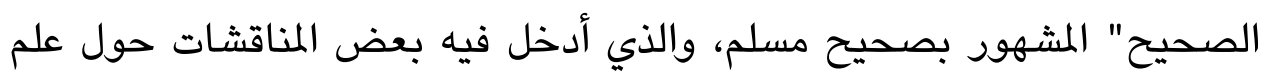

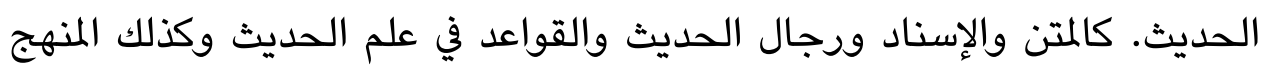

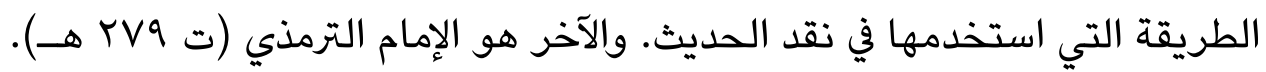

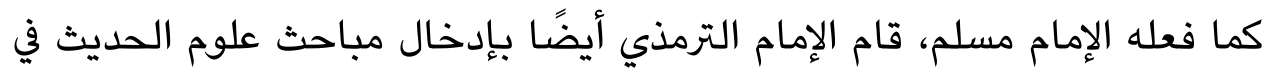

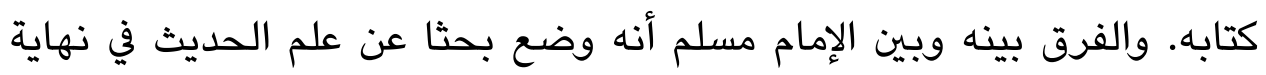

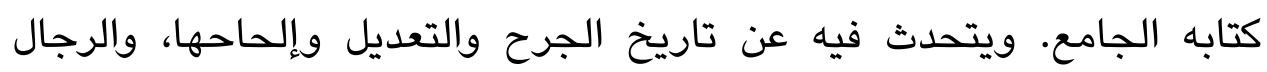
والشحصيات في علم الجرح والتعديل والاختلافات الموجودة في عملية تضعيف التعايف

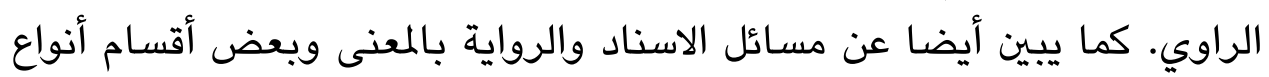
الحديث، مثل الحديث الصحيح والحسن والمرسل والمنكر وغيرها.

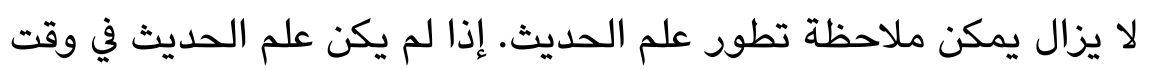
سابق مكتوبًا بشكل منفصل وعلى وجه التحديد، كما فعل الشافعي والإمام مسلم 
والترمذي بإدخال مباحث علم الحديث في رسائلهم وفي المقدمات وفي ملحقات كتبهم. وهكذا بدأ التطور التالي لعلم الحديث أنه يُكتب بالتحديد في الكتب

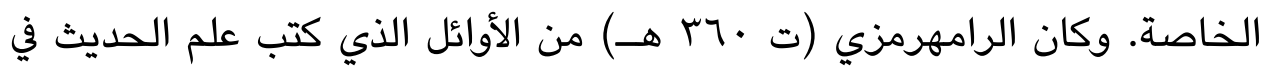

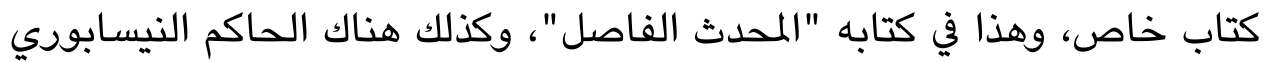
كما سبق ذكره. كأول من أدخل علوم الحديث كفرع للمعرفة في الكنوز الإسلامية،

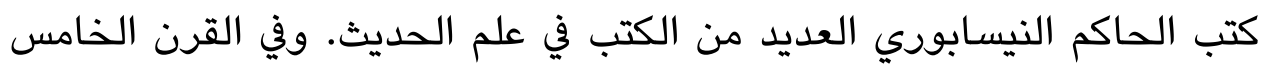

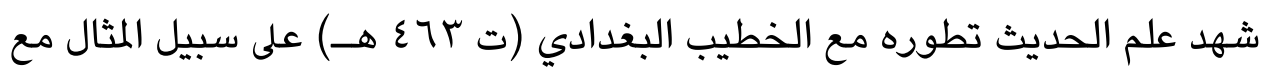
كتابه "الكفاية في قوانين الرواية" (al-Jawâbî 1991, 74-77). هنا لمحة عن نشأة علم الحديث في العملية والتطبيق ليحافظ على ألى أصالة الحديث النبوي وإلى أي مدى استمر هذا العلم في النمو والتطور حتى القرن الخامس على الأقل عندما تم إدخال علم الحديث رسمياً كفرع من العلوم الإسلامية.

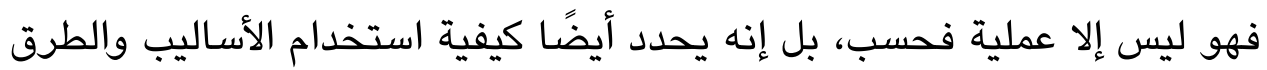
والمنهجيات في نقد الأحاديث ودراستها.

\section{نقد متن الحديث}

كل حديث نبوي كما هو المعروف يتكون من المتن والسند. ويشمل المتن

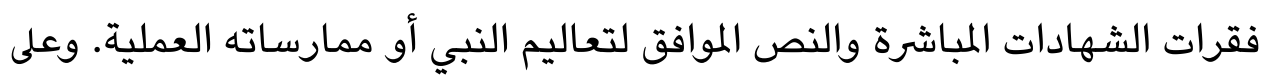

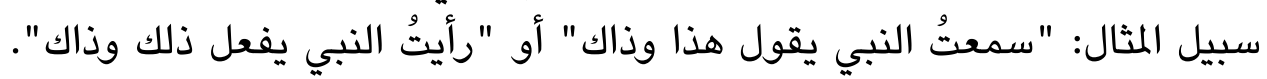
يحتوي المتن على اقتباس دقيق مَن سمع وشاهد كلمات النبي أو وصفا لأفعاله

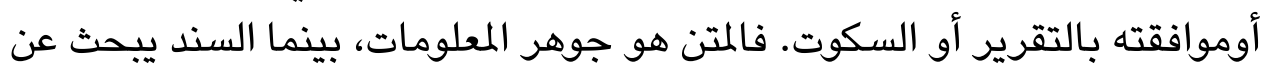

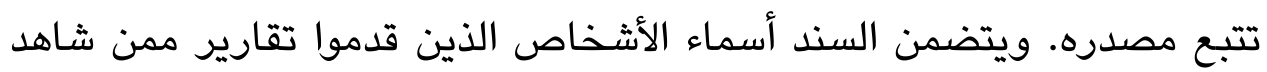
وقت ورود الحديث أو تسجيله (Karcic 2006, 205). إنتقد مجموعة من المستشرقين الحديث النبوي بل وتهاجمه باعتباره المصدر الثاني للتعاليم الإسلامية. وكان من هدفهم إثارة الشكوك لدى المسلمين

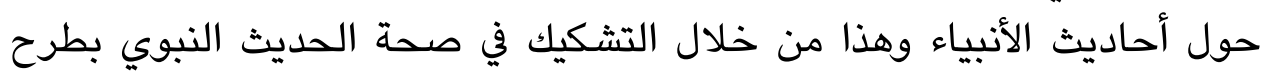
السؤال عن المنهج والطريقة التي استخدمها علماء الحديث في تأهيل الحديث على في 
أساس نوعيته. ويعتقد البعض منهم أن نقد الحديث الذي كان لدى العلماء هو فقط نقد للسند ويقوم علماء الحديث في تحديد نوعية الحديث فقط بالنظر على منى سند الحديث ودون النظر إلى جودة متن الحديث. فبالنسبة لبعض المستشرقين،

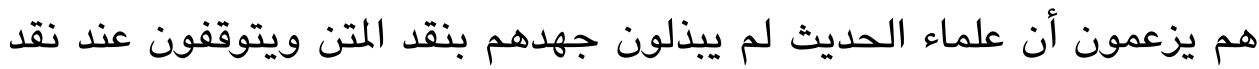
السند وحده. ومن بين المستشرقون الذين يقولون ذلك: إجناز جولدتسيهر في

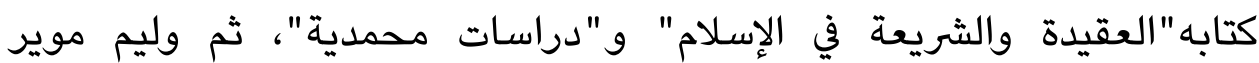
(ت William Muir بعض المستشرقين.

وعلى الرغم من أن نقد المتن للحديث النبوي قد تم تطبيقه عمليا منذ عصر النبوة من قبل الصحابة. فأصحاب النبي صلى الله عليه وسلم هم أولئك الذين مارسوا بثقة وحزم ما سمعوه مباشرة من النبي، وما شاهدوه مباشرة من سلوك

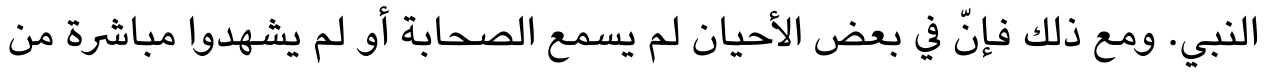
النبي. هم يحصلون على حديث النبي من خلال الصحابة الأخرى ويتفقونه

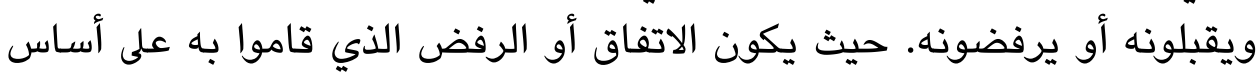
فهمهم للقرآن والأحاديث الأخرى التي سمعوها من النبي (al-Adlabî 1983, 105).

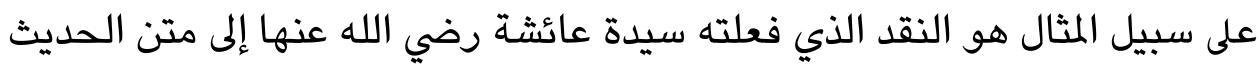

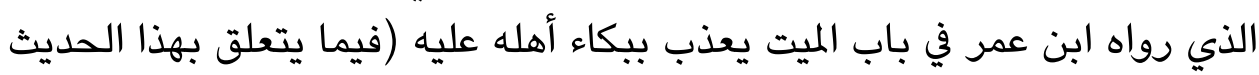
سيشرحه الباحث كمثال في باب نقد متن الحديث).

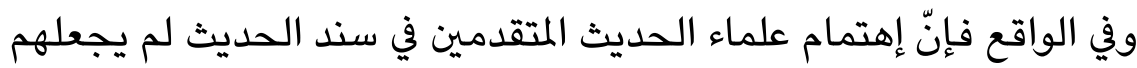
مزعومين بأنهم يتخلون عن نقد المتن عمداً بل لعلماء الحديث المتقدمين أيضا الإهتمام الكبير بمتون الحديث. فيمكن قول ذلك بوجود كتب علم الحديث التي

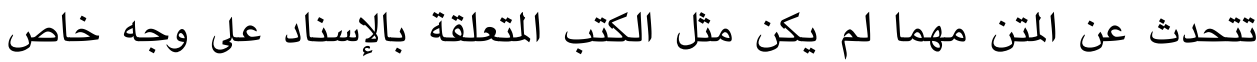

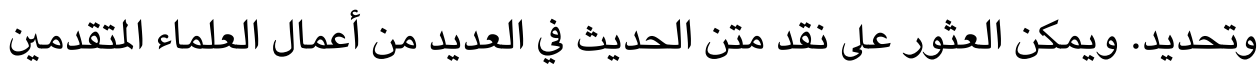
وخاصة من بين الفقهاء. كيف يفسرون العلاقة بين متون الأحادث بعضئ فضهاء البعض. سواء كانت تقوّي أو تضِّف بعضها البعض، وما بف المسار الذي يسلكونه عند وجود التعارض بين متون الأحادث ظاهرها. 
وسيكون من السهل جدًا العثور على الكثير من أعمال علماء الحديث

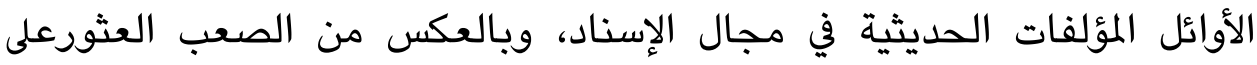

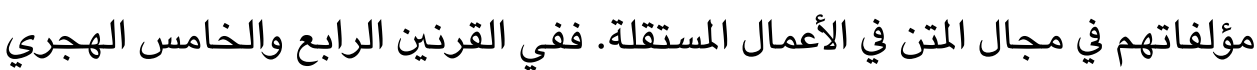
سنجد أعمالًا تناقش نقد المتون بشكل مفتوح واضح. فمن الجدير بالفهم على أن الن النمال ذلك كرد فعل للحركة والتطور السريع للعلم والفكر والتدوين والجمع والتهن والكتابة. ظهر في القرن الرابع الهجري جملة من الحفّاظ. وكان من بينهم ابن

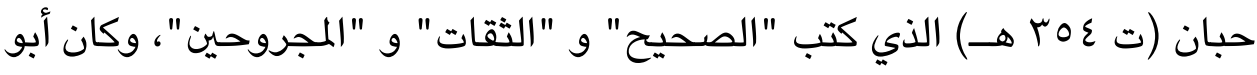

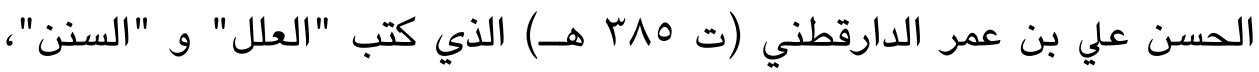

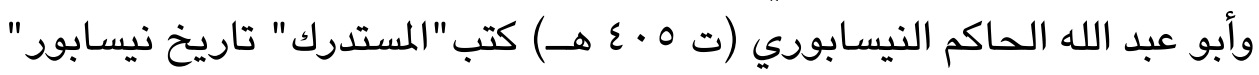
و "معرفة علوم الحديث". وفي القرن الخامس الهجري، كان هناك أيضًا بعض هض

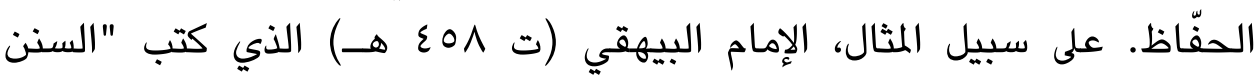

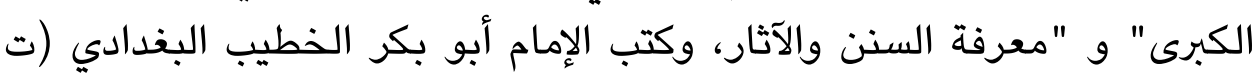

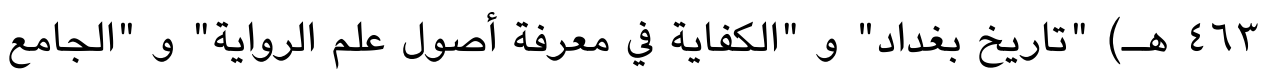
لأخلاق الراوي وآداب السامع" (Khalaf 1989, 15). وهذه كلها توضح لنا إهتمام

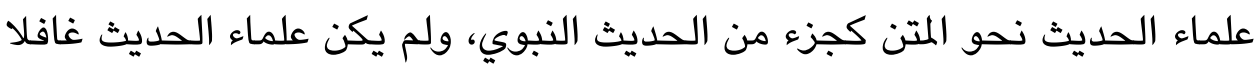

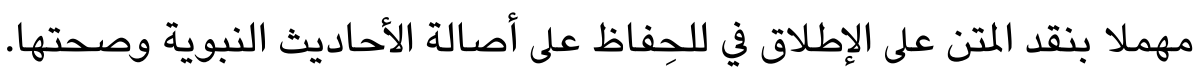

\section{طرق عملية نقد متن الحديث}

إن النقد على متن الحديث كخطوة متقدمة في بحث الحديث ودراسته يرتبط ارتباطًا وثيقًا بنقد السند. ولا يمكن إنكار ذلك من خلال النظر على ما كان

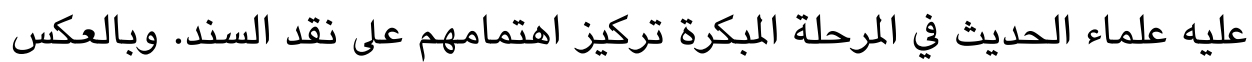

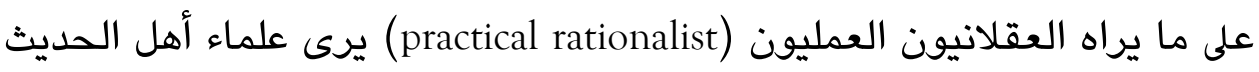
أن السند والمتن لها المنزلة والمكانة المتساوية كجزء من حديث نديون اهبوي، فالسند بلدون متن مستحيل والمتن بدون سند لا معنى له. وهكذا المعيار الأول للقيام على نقد متن الحديث، هو التأكد من أن للمتن

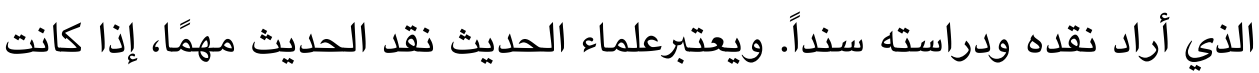


إسناده معروفة بقوة جودته وصحته. إذا كانت الإسناد قوية فيمكن الانتقادعلى المتن، ولكن إذا كانت الإسناد ضعيفة فلا حاجة للنقد على المتن. لأن نوعية المتن

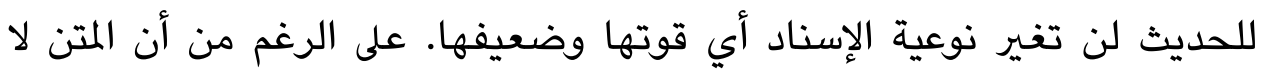
تتعارض مع قواعد صحة المتن، فلا يمكن للمتن أن تغيير ضعيفية الإسناد.

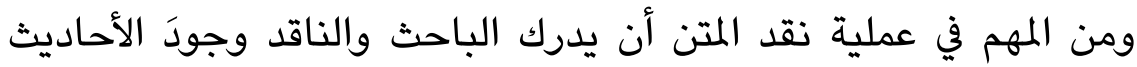

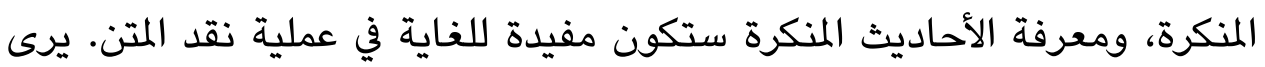

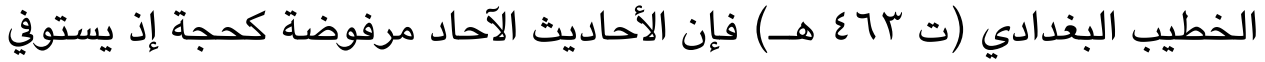

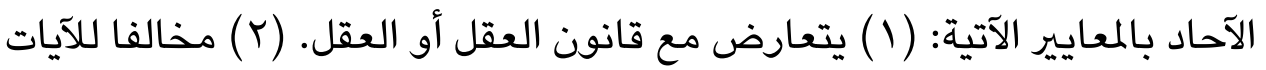

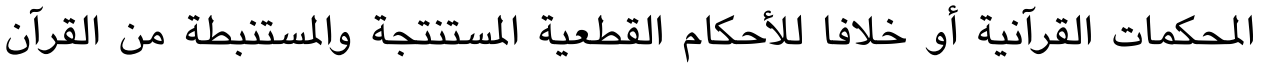

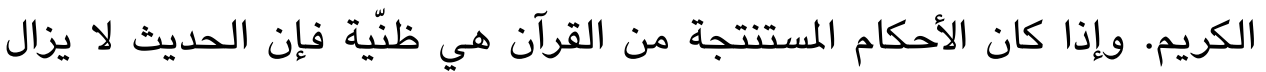

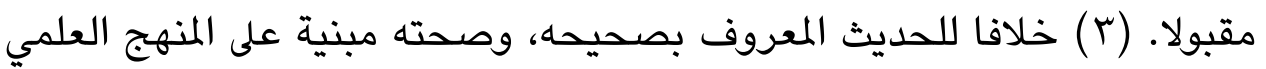
وليس على مجرد الظنّ. (ع) خلافا للعرف والتقاليد السائدة في المجتمع القائمة على المانى

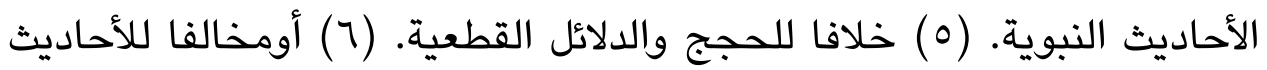

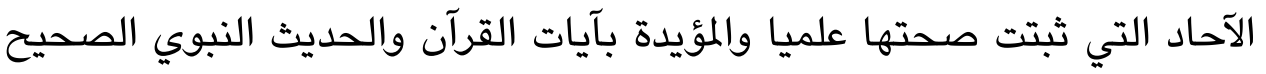

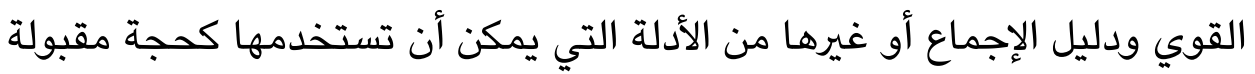
.(al-Adlabî 1983, 236)

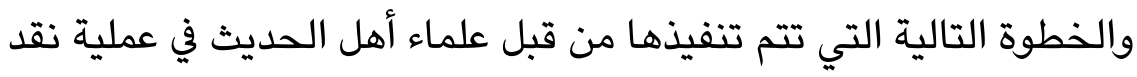

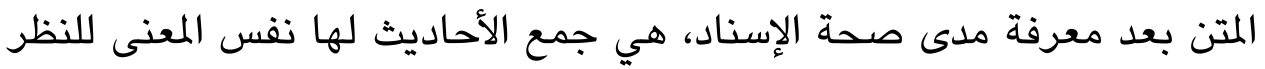

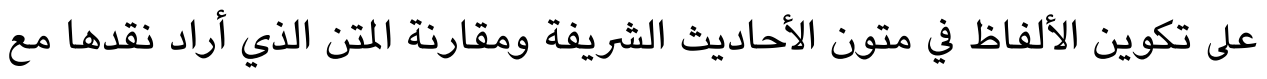

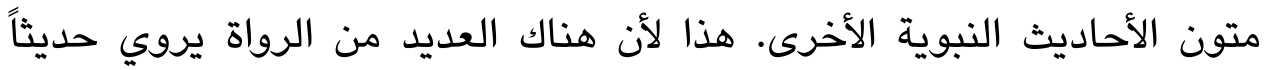

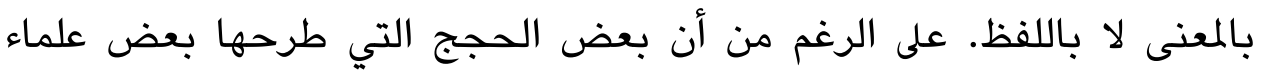

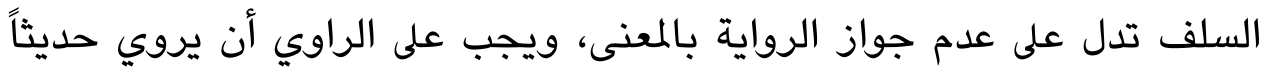

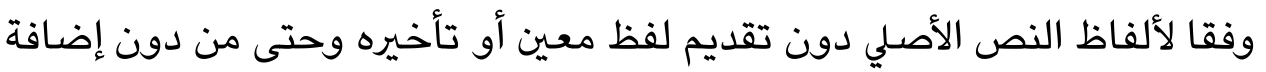

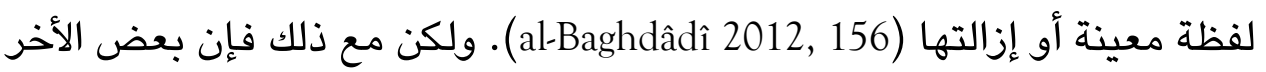

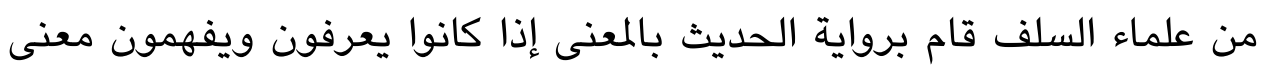

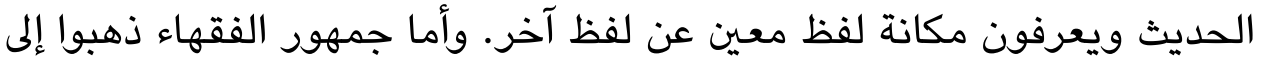


جواز الرواية بالمعنى خاصة عند أهل العلم الذي يفهم موقف الخطاب وكذلك المعاني الواردة في المتن (al-Baghdâdî 2012, 176).

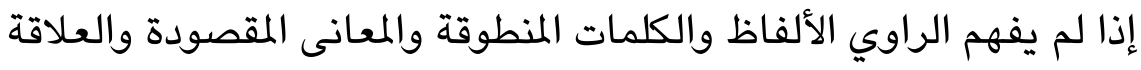

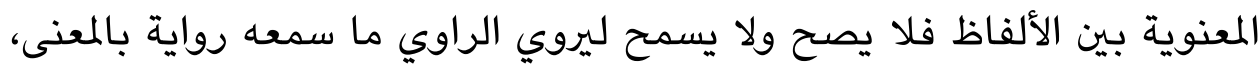

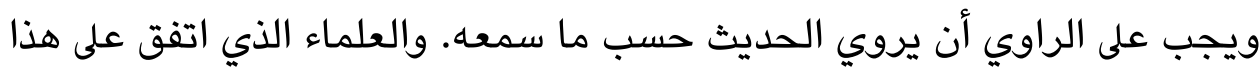

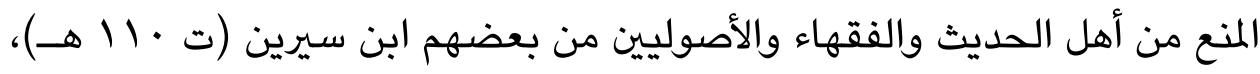

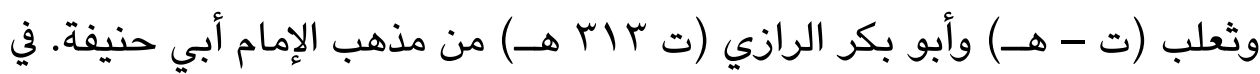

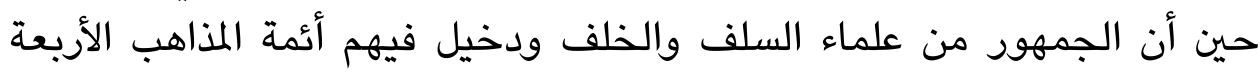

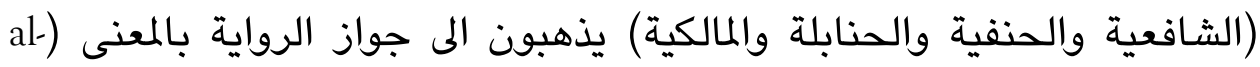

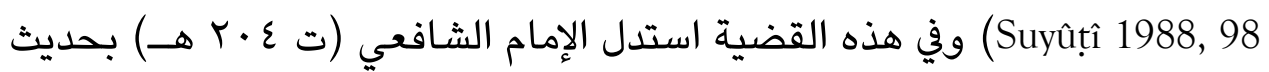

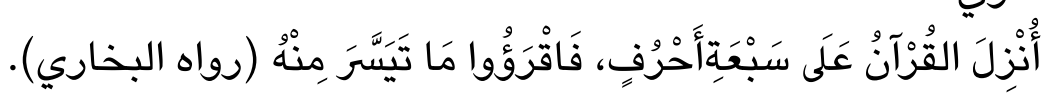

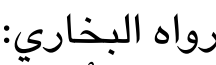

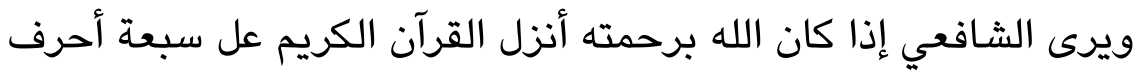

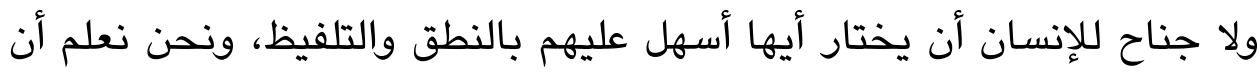

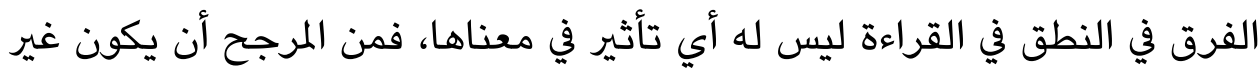

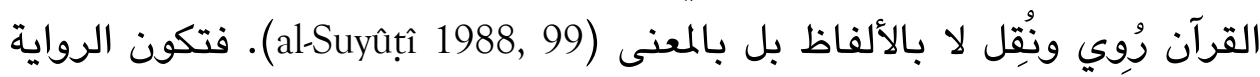

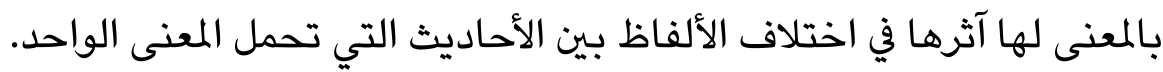

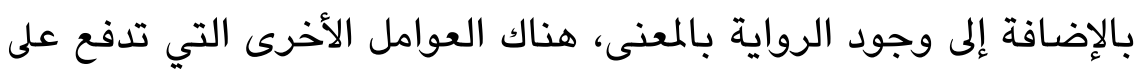

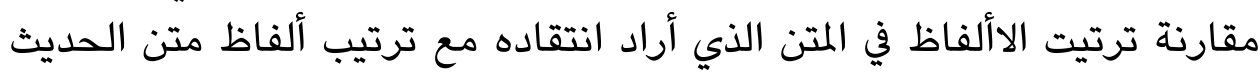

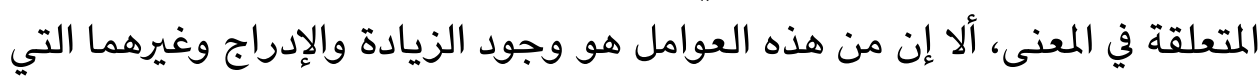

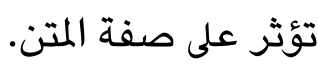

الزيادة هنا هي زيادة في المتن. والمقصود بالزيادة إذا أضاف الراوي لفظا

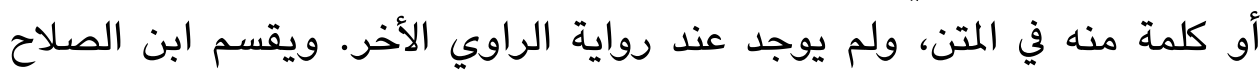

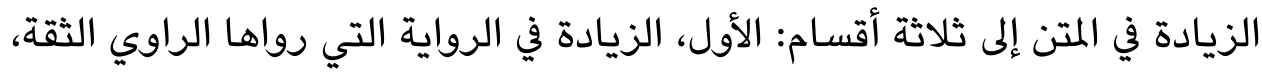

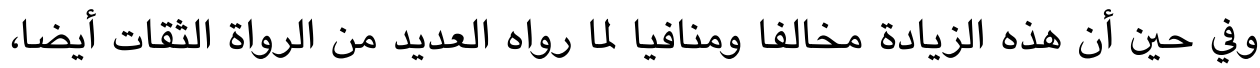


فحكم هذه الزيادة مرفوضة مردودة. والثاني، الزيادة في الرواية التي رواها

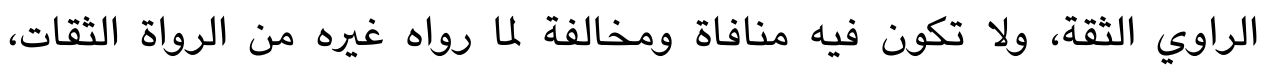
فحكمه عند ابن صلاح هذا مقبول. الثالث، الزيادة في الرواية التي رواها الثقة ولم يذكرها سائر من روى ذلك الحديث (al-Ṣalâh 1986, 86). ولم يعط ابن الصلاح أي يعليق في النوع الثالث من الزيادة الثاد كما ذكرناه.

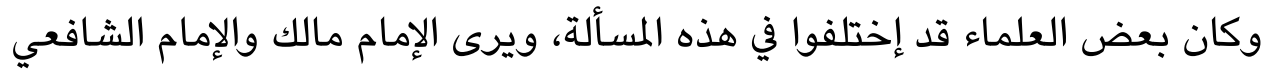

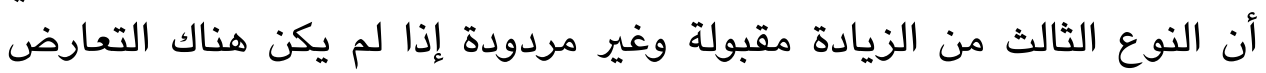

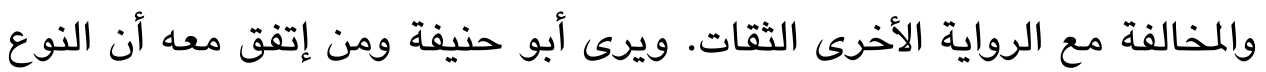

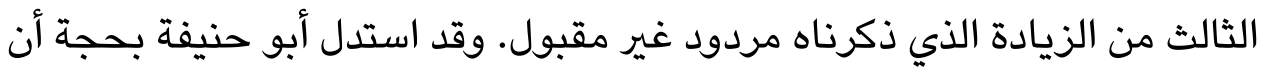

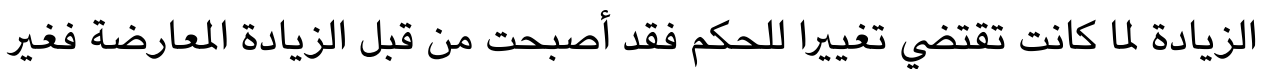
مقبولة ('Itr 1979, 426).

وأما الإدراج في متن الحديث الذي يمكن تحديده ومعرفتهه من خلال

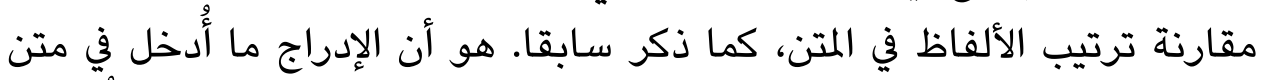

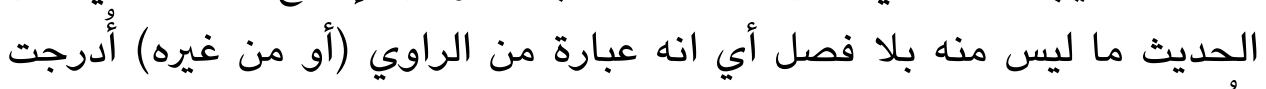

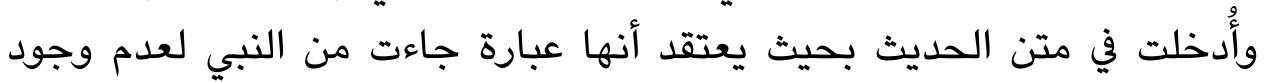

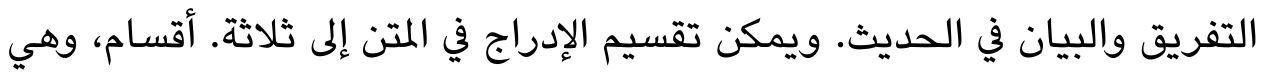

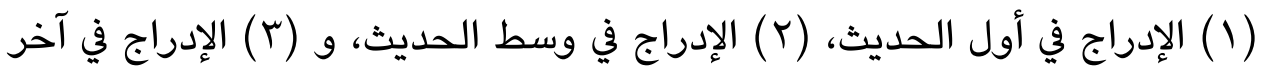
الحديث (al-Ṭahhân 1996, 104).

ومن الأنواع الثلاثة للإدراج في المتن التي ذكرنا سابقا، فإن الإدراج في آخر

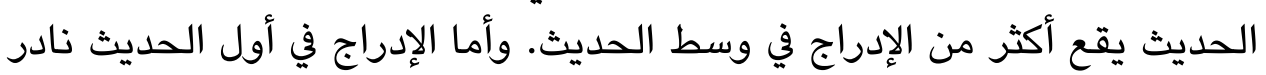

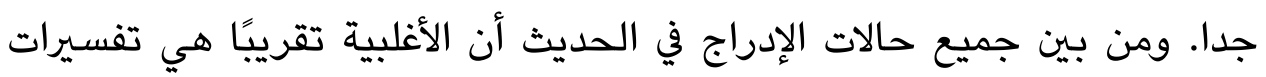

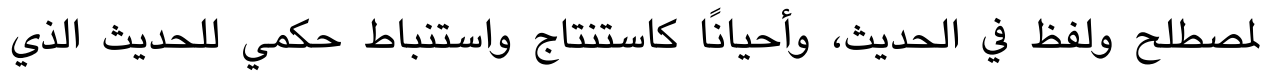
يعتبره المستمع أو الراوي جزءًا من الحديث فأدخله في متن الحديث ( Itr 1979, ' .$(440$

والمثال من الأحاديث التي تحتوي الإدراج في أول متنه هو الحديث النبوي

عن الوضوء رواه الخطيب البغدادي مخرِّا. 


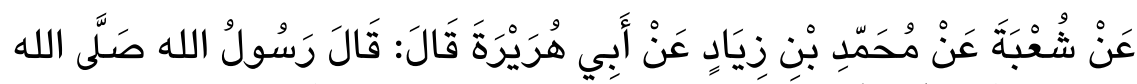

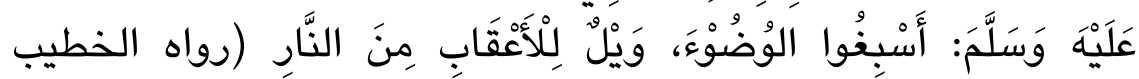
البغدادي من رواية ابن قطن و شبابة).

فبعض اللفظ والكلمة في متن هذا الحديث ليست كلمة النبي صلى الله عليه

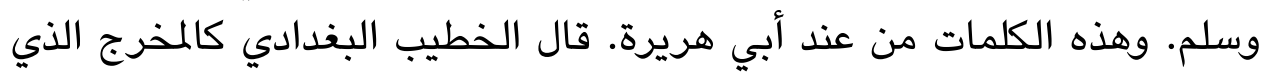

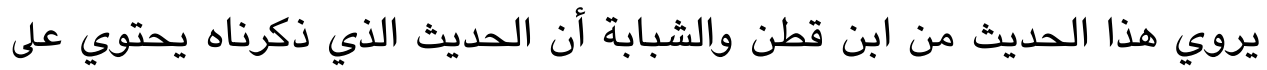

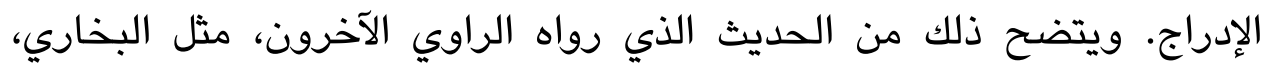

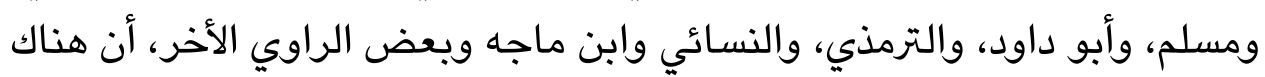
خلاف في لفظ المتن (al-Suyûtîn 1988, 168).

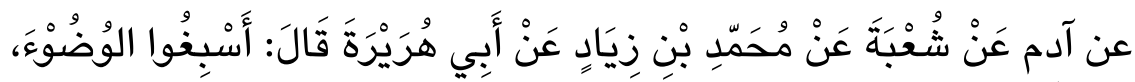

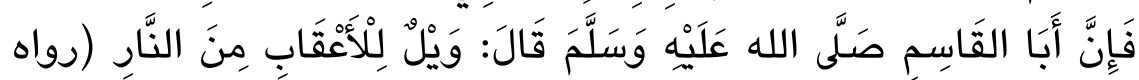

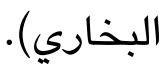

ومن رواية البخاري، نرى بوضوح مكان الإدراج في الحديث الذي أخرجه

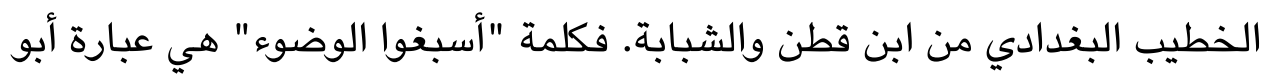
هريرة استنبطها من حديث النبي الذي سمعه. وبالإضافة إلى الإدراج والزيادة في المتن كما بيّنّاه، تساعد مقارنة تركيب اللتي

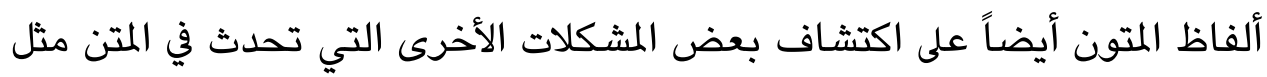

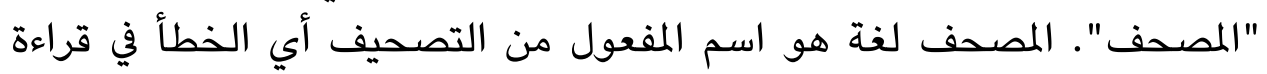

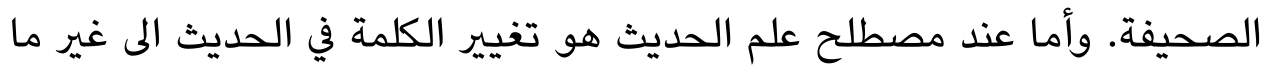

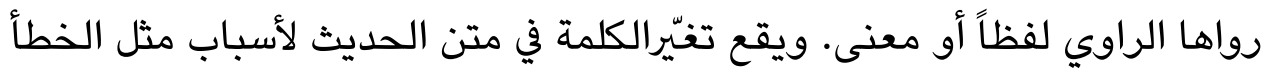

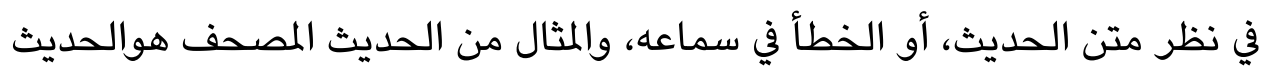

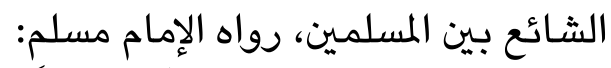

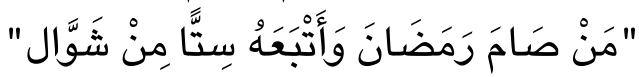


هناك تغيير في الكلمة التي رواها أبي بكر الصولي عن أبي أيوب الأنصاري، فهو

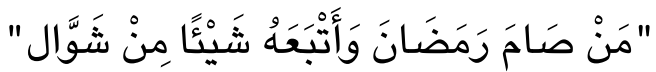

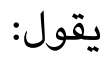

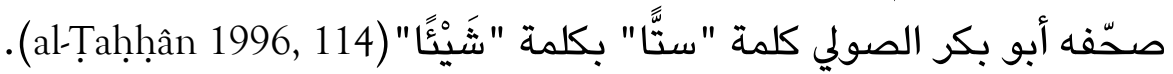

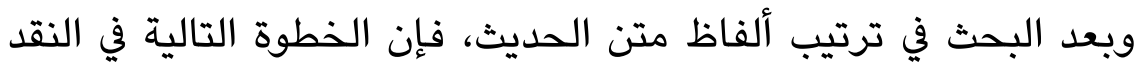
على متن الحديث هي إجراء بحث حول محتويات مضمون المتن المقدئ المتود نقده.

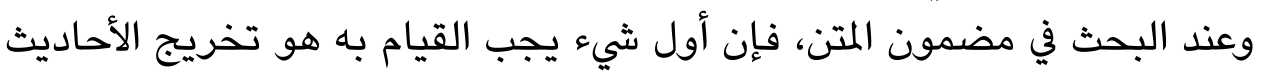

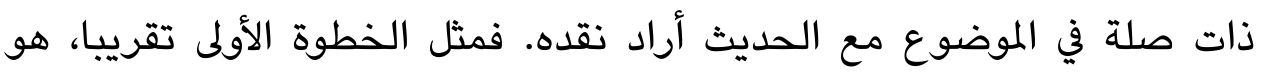

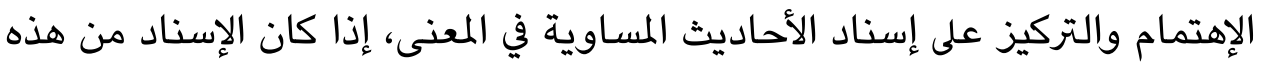
الأحاديث قويًا فإن البحث مستمر. الإنمان

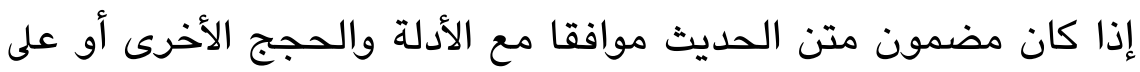

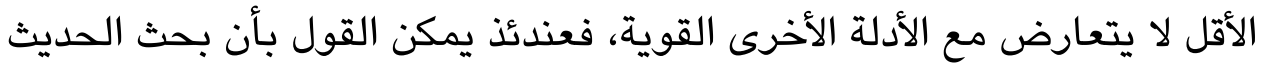

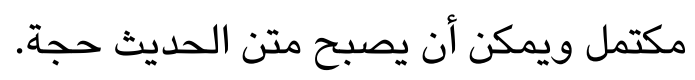
ويرى الخطيب البغدادي، فإن القاعدة المستخدمة في تقييم صحة متون

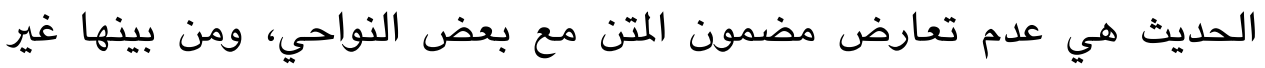

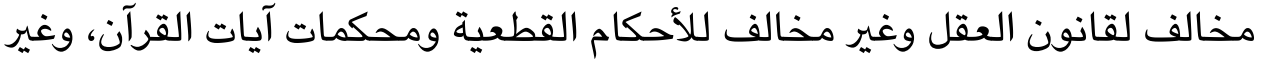

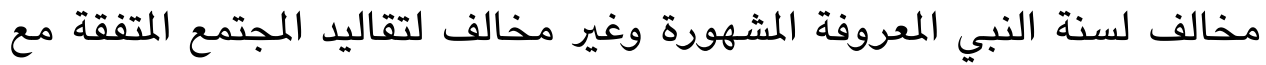

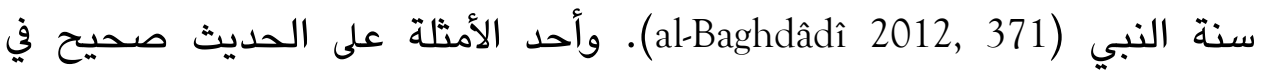
الإسناد، ولكن المتن مخالف بالأدلة الأخرى أقوى منه:

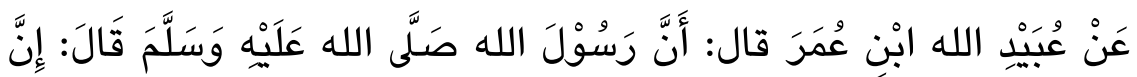

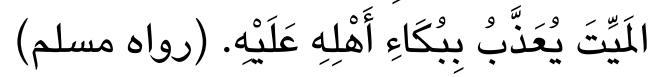

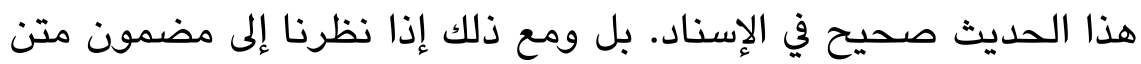

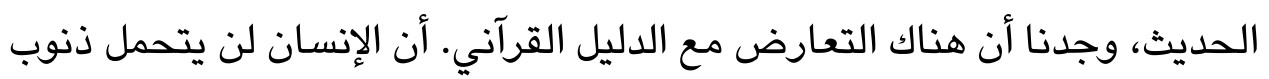

$$
\begin{aligned}
& \text { إنسان آخر. يقول الله تعالى: }
\end{aligned}
$$

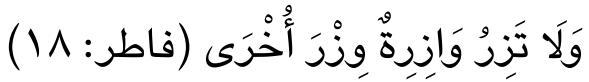


وتنكر عائشة رضي الله تعالى عنها الحديث الذي رواه ابن عمر السابق

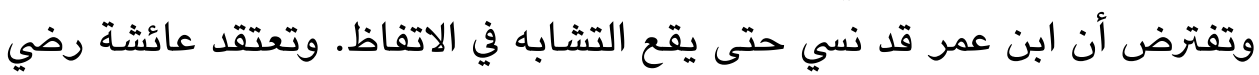

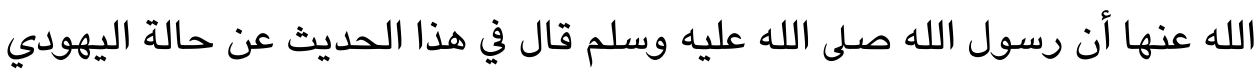
الذي يُعذّب في القبر وأهله يبكون عليه. فلذلك فإن الغرض الحقيقي من الحديث لا

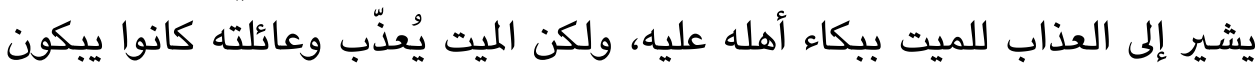

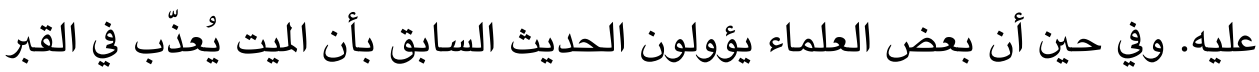

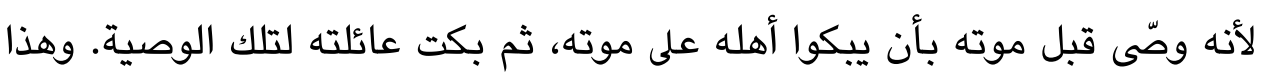

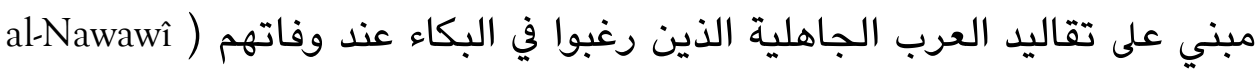
. (2001, vol. 3, 505

ثم إذا كان متن الحديث المراد بحثه يبدو أنه يتعارض مع الحديث الآخر،

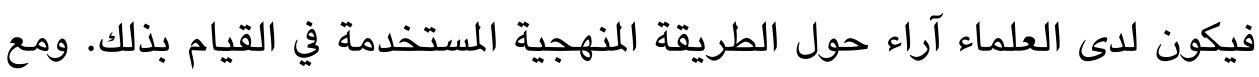

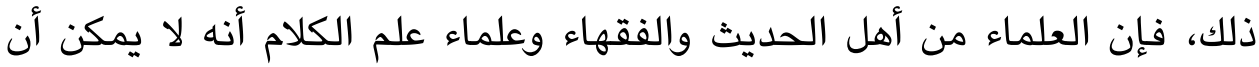

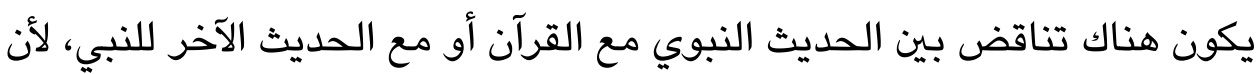

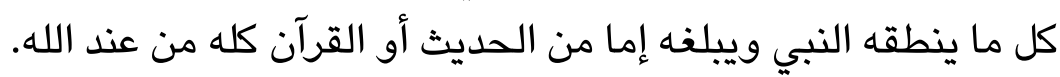

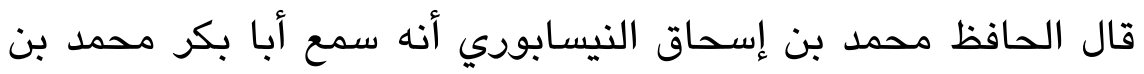
إسحاق بن خزيمة (ت الس هـ) يقول: "لا أعرف أنه روى عن رسول الله صلى اله اله الله عليه وآله وسلم حديثان بإسنادين صحيحين متضادان فمن كان عنده فليات

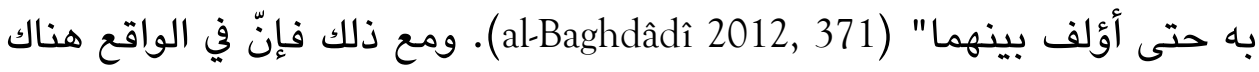
بعض الأحاديث مع سند صحيح الذي يبدو أنه يتعارض مع الأحاديث الصحيحة

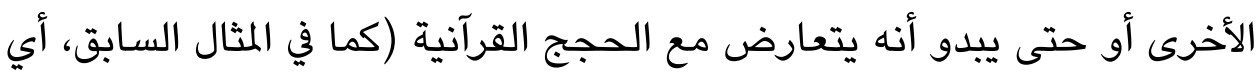
الحديث المتعلق بتعذيب الميت بسبب بكاء عائلته عليه المخالف بالحجج القبه القرآنية).

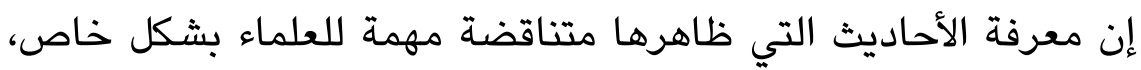

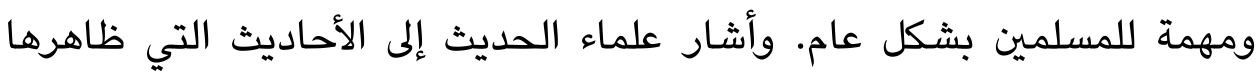

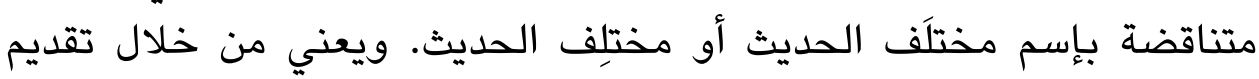
الحديثين الذان كأن ظاهرهما متناقضان في معانيهما. ثم التوفيق بين معانيهما والعمل بهما، أو بترجيح أحدهما والعمل به وترك الآخر. 
والعلماء المتخصصون الحديث والفقه وعلم الأصول، التي هي قادرة على

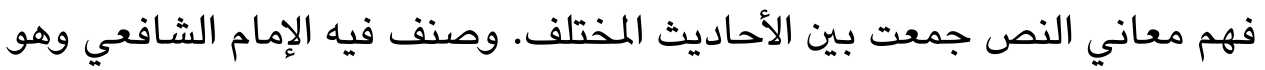

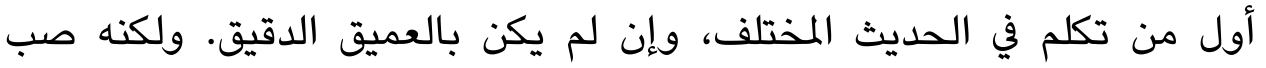
اهتمامه على الحديث المختلف كما هو مذكور في كتابه "الرسالة" و "الأم" مع بيان وئ وان

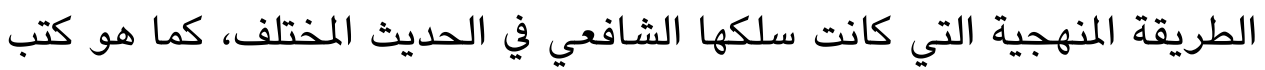
أيضاً في كتاب "إختلاف الحديث". وصنف ابن قتيبة (ت TV7 هـ) عن "أشياء حسنة" و "أشياء غير حسنة"، بافتراض أنه عندما يأتي حديثان متناقضان ظاهراً

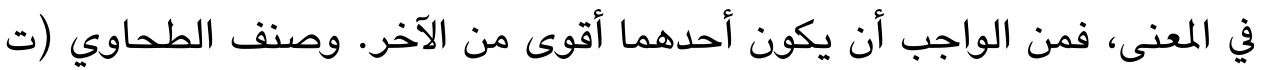

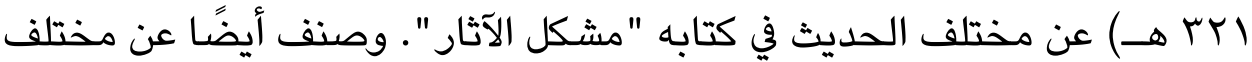
الحديث ابن جرير (ت • آ هـ) وابن خزيمة (al-Suyûtî 1988, 196).

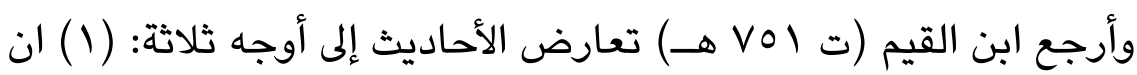
يكون كلاما غلطا لبعض الرواة الثقات. (Y) أن يكون أحد الحديثين ناسخا للحديث الآخر. (r) أن يكون التعارض في فهم السامع لا لا في نفس كلامه صلّى الله

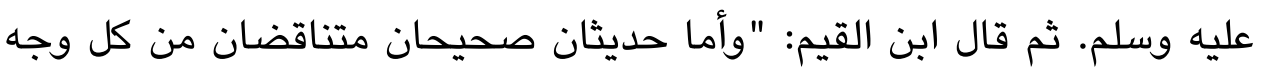
ليس أحدهما ناسخا للآخر فهذا لا يوجد أصلاً". أما بالنسبة للنقطة الأولى لا يمكن من فئن

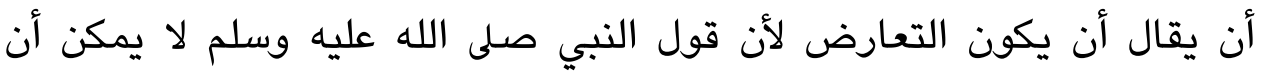

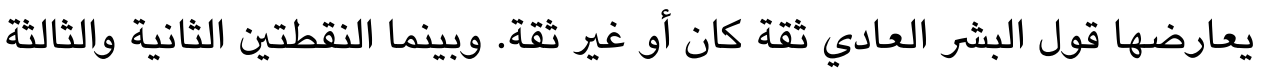
فهما سبب تعارض الحديث ظاهراً (al-Jawâbî 1991, 370).

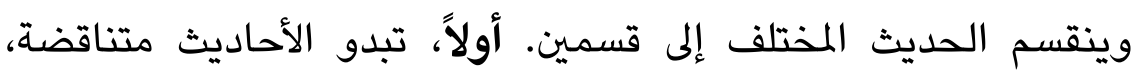
ويمكن الجمع والتوفيق بينهما بوجه صحيح فلا يصار إلى التعارض ولا النسخ.

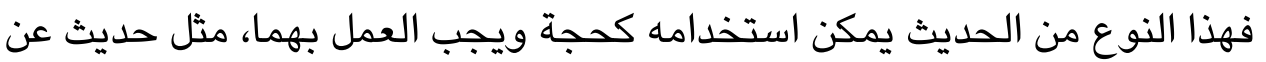
طهور الماء إذا بلغ قلتين. ثانياً، تبلو الأحاديث متناقضة وليس لدئ لديها إمكانية

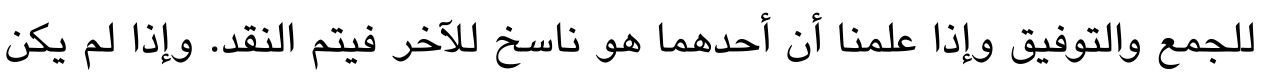
كذلك، فيتم ترجيح أحدهما عن الأخر (al-Suyûtî 1988, 198). وأما عملية الترجيح ممكنة في مختلف جوانب الحديث. كالترجيح من خلال الترال صفات الراوي مثل مستوى حفظه وإتقان علمه وكثرة حفظه وإتقان لغته منه 
وشهرته ومسؤوليته على ما يعرفه وبعض جوانب أخرى في الراوي. ثم الترجيح

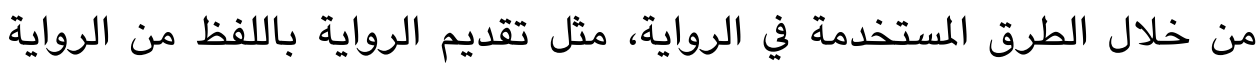
بالمعنى، وتقديم الرواية المصحوية بسبب ورودها مما لم يتبعها سبب الورود. ثم الترجيح من خلال الألفاظ المستخدمة في الحديث، مثل تفضيل الحديث بلفظ المعنى الحقيقي من الحديث بلفظ المعنى المجازي، والعديد من المناهج التي يمكن

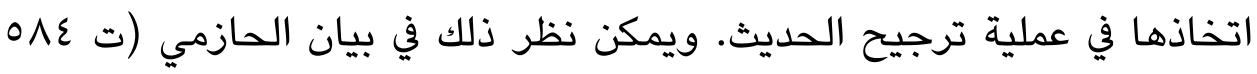

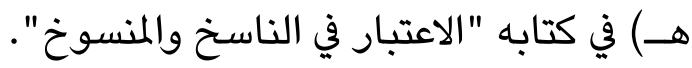
وإذا تم تنفيذ الترجيح بجميع أساليبه وطرقه المنهجية ولا تقدم نتائج مقنعة، فإتفق علماء الحديث بالوقوف والتوقف، ويبدو أن حكم الحديثين قابل للعمل حتى يتم البيان الواضح. هذا مبني على الإعتقاد الأول أنّ من المستحيل على أنى إنى النبي أن يبلّخ شيئًا متناقضًا متعارضاً.

\section{باراديم نقد متن الحديث}

الكلام والمناقشة عن النموذج أو الباراديم الذي يستخدمه علماء الحديث في

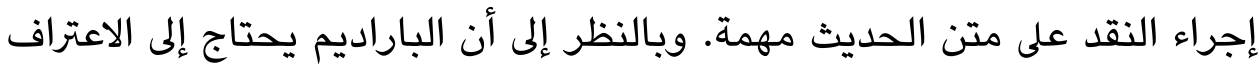
به ودراسته من حيث ملائمته في العصر الحديث، فإن الأكاديميين الحديثة في

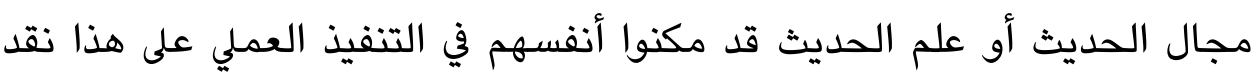

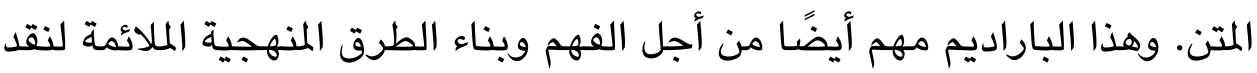

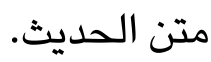

ويعتبر الباراديم كأساس التفكير وإطاره قيمًا عمومياً يتم أخذها في

الاعتبار عند تصميم الطريقة المنهجية التي ستعمل عند البحث. وعند الإشارة إلى إلى مختلف المؤلفات والمصنفات في علم الحديث، لم يجد الكاتب أو الباحث بوضوح الباراديم المعتمد، فلذلك يحاول الكاتب التتبع عليه من خلال الأساليب الاستقرائية، يعني بأخذ قيمة عمومية يمكن القول على أنها مرجع الطرق المنهجية التي يستخدمها علماء الحديث في إجراء النقد على متن الحديث. 
ومن البيان السابق للطريقة التي استخدمها علماء الحديث في نقد المتن،

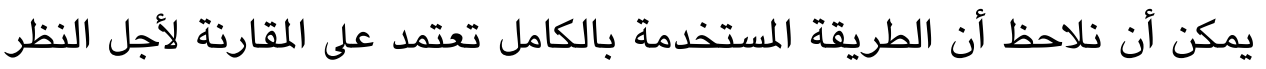

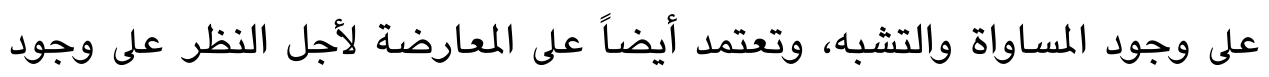

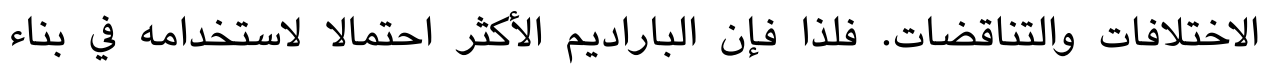

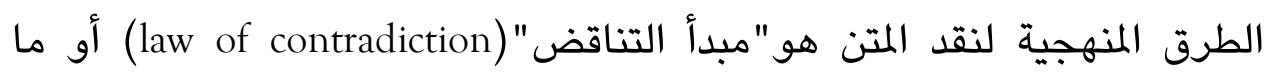

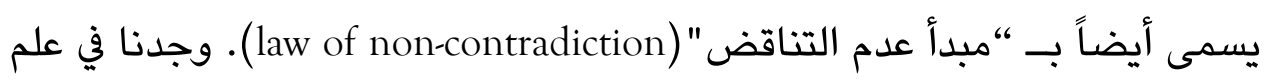

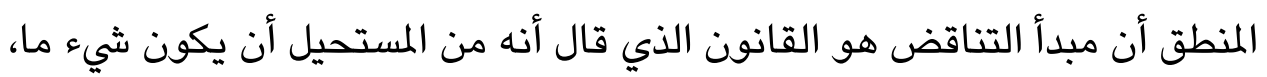

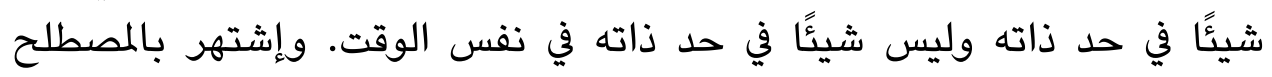

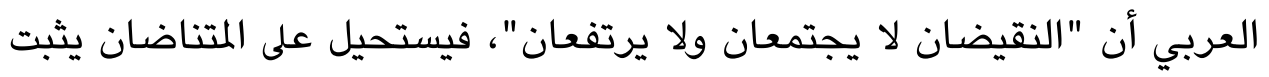

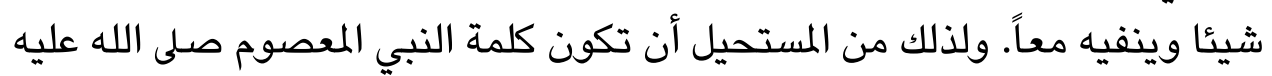

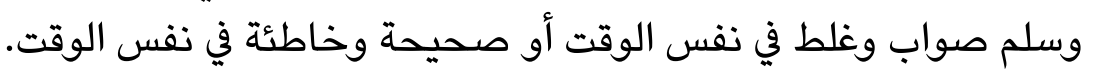

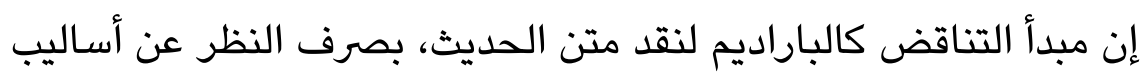

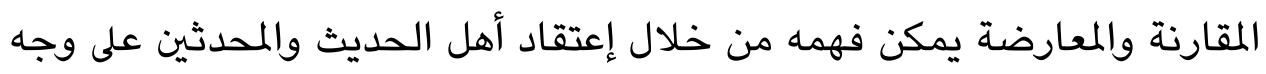

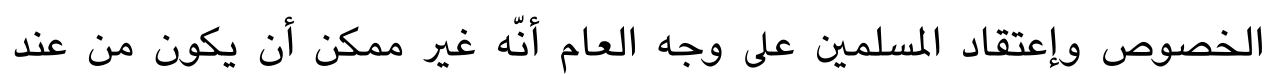

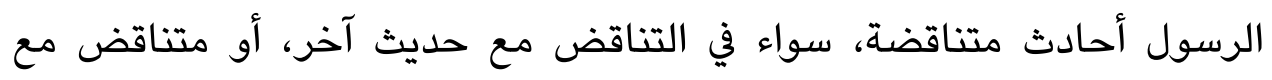

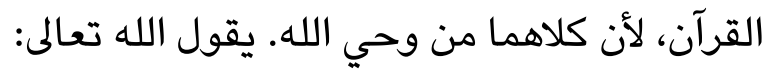

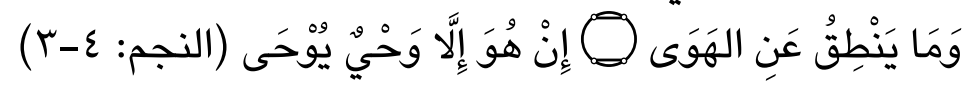

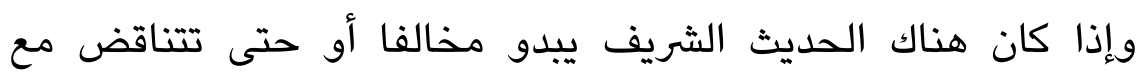

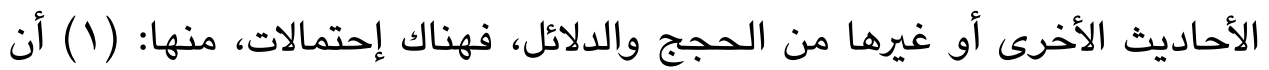

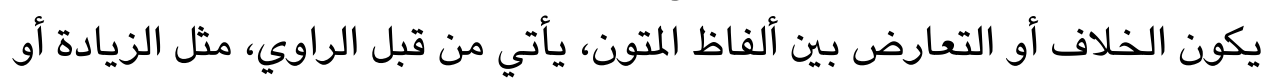

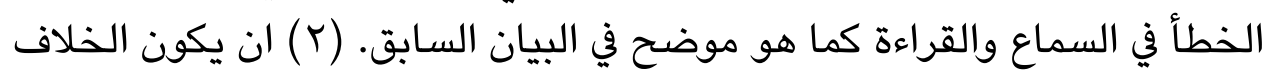

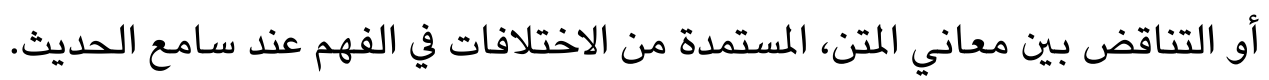

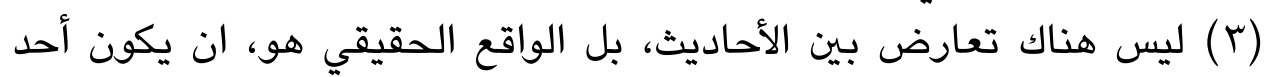

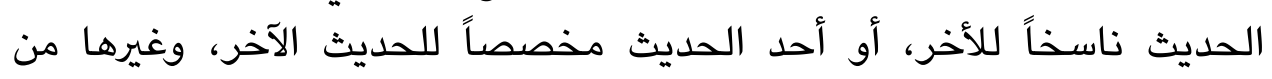

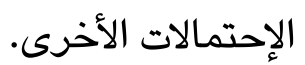


فلا يزال مبدأ التناقض كالباراديم للنقد على المتن وكمنهجيته المشتقة المستخدمة من قبل علماء الحديث مناسبًا وملائما جدًا للاستخدام في العصر الحديث. ولا سيما بسهولة الوصول إلى المصنفات والمؤلفات المختلفة، فستكون المقارنة والمعارضة كعملية نقد الحديث أكثر فعالية.

\section{تحول نقد المتن في العصر الحديث}

العصر الحديث بكل تطوره مع تقديم العديد من الفوائد والسهولة مثل

عملة ذات وجهين، تجلب التطورات التكنولوجية الحالية في العصر الحديث أيضًا العديد من الأشياء السلبية للمجتمع. لذا كباراديم والطرق المنهجية المشتقة منها،

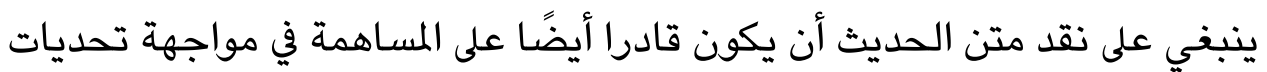

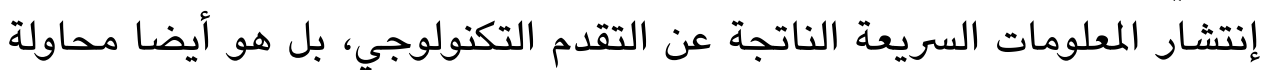

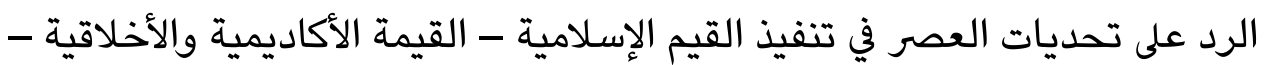
التي صالحة في كل الزمن والمكان. وفي ضوء هذه القضايا يرسم الباحث تحول نقد المتن في عصر الحديث إلى اتجاهين، يعني التحول الداخلي والتحول الخارجي. ويعتبر التحول بمثابة تغيير في

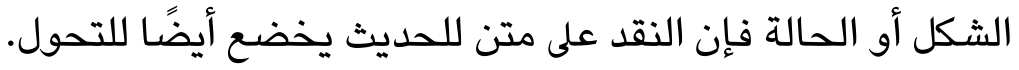
الأول، التحول الداخلي. بالنظر إلى عملية بحث الحديث ودراسته وخاصة الفئ في نقد المتن، أنه ليس هناك الكثير من التغييرات الهامة في باراديمه ومنهجيته، بالئه ومبدأ التناقض كباراديم لا يزال يستخدم كأساس لنقد المتن. وفي المجال العملي لئي فمن العصر الكلاسيكي إلى العصر الحديث لم تتغير الباراديم والمنهجيات المستخدمة كثيرًا. وهو يبدأ نقد المتن من خلال النظر إلى صفات الإسناد، ثم فحص

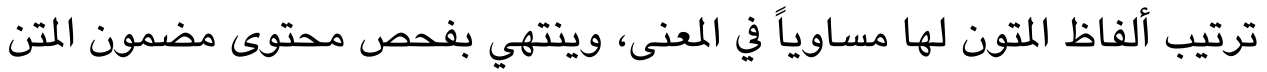

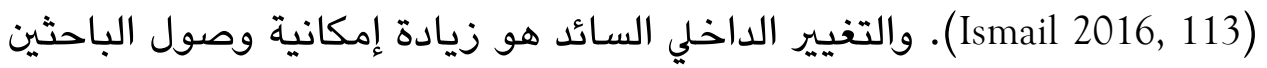

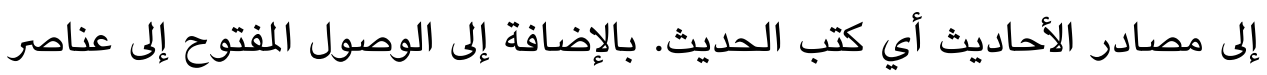

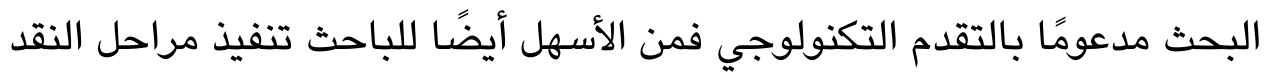
المتن، مثل جمع الألفاظ المترادفة في المعنى من مختلف متون الحديث الحديث. 


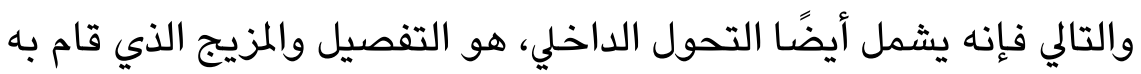

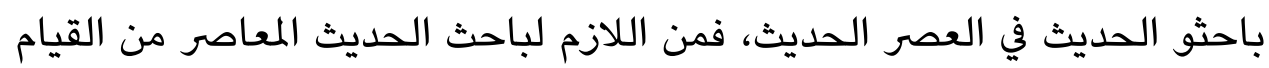

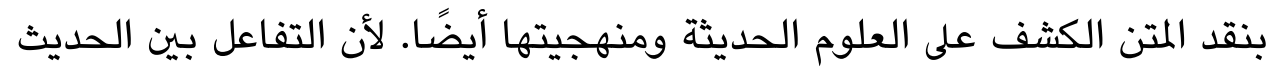

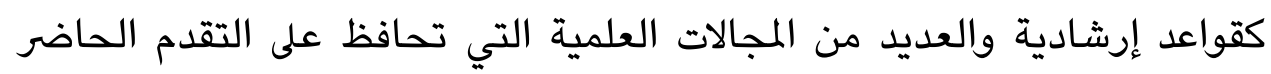

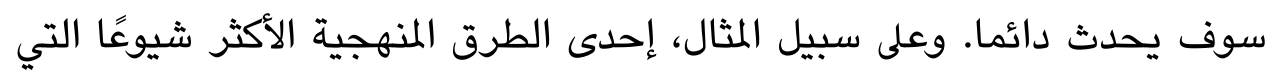
يستخدمها المفكرون في هذا العصر الحديث المعاصر هي الطريقة المرئ التأويلية أو مأ

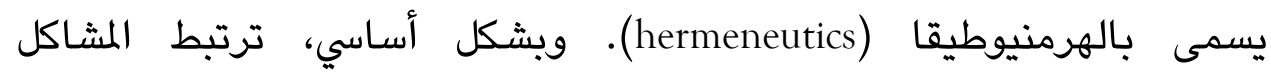

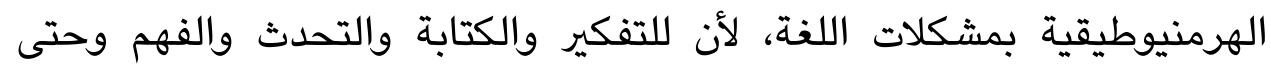

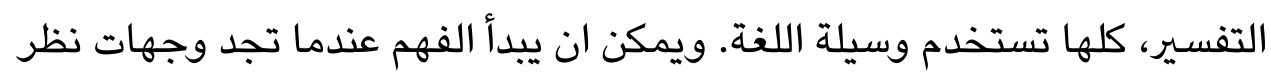

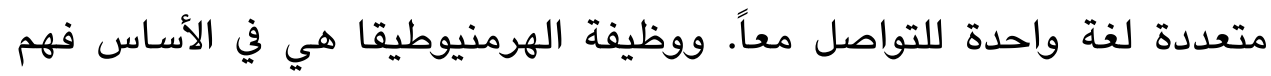

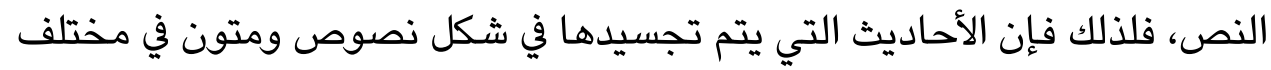

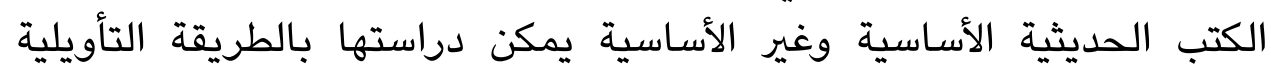
الهرمنيوطيقية (Suryadi 2015, 183). وهو أيضًا كاستمرار لوظيفة الأليفة نقد المتنا

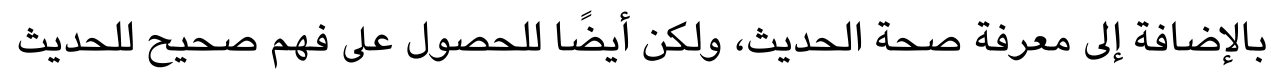
ولتطبيقه.

الثاني، التحول الخارجي. إنها محاولة لتحويل باراديم النقد على المتن

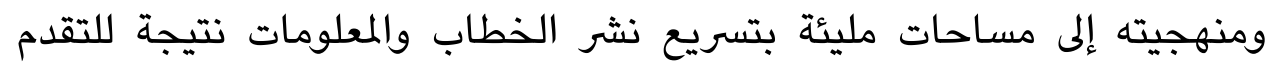

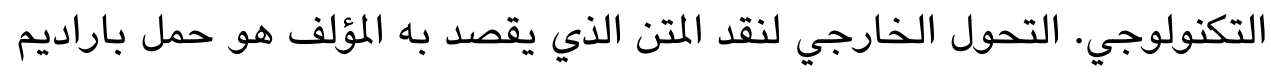

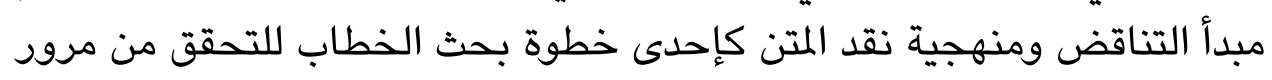

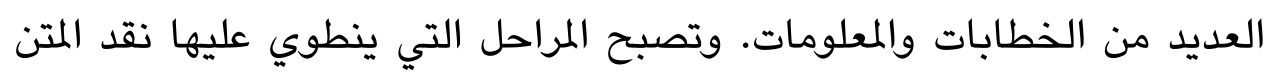

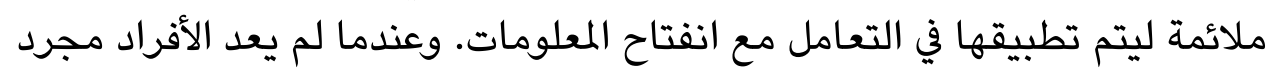

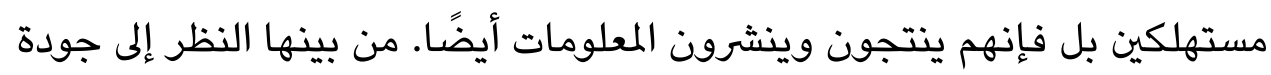

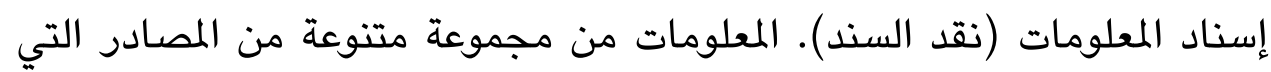

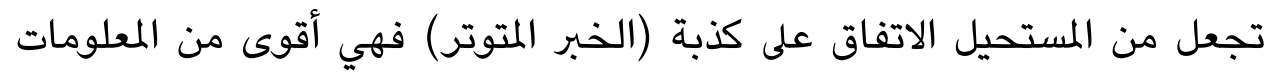

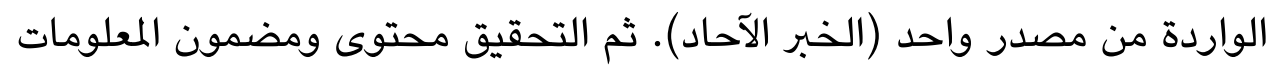

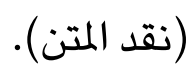


عirman ) علد تحليل الخطاب والمعلومات وفقًا لنورمان فاركلوف - (Fairclough هناك حاجة للتمييز بين النص والخطاب أوالحوار، ومن خلال النظر إلى النص كجزء من الخطاب فليس النص على شيء مستقل تخلى عن البيئة الاجتماعية. وإذا

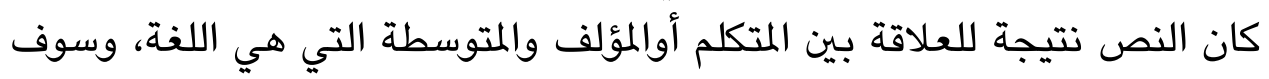
يكون النص تلقائيا في المنطقة والعصر والمجتمع التيبيدو فيها النص. فئي في تحليل المعلومات النص هو الشيء الرئيسي للبحث. وينبني تحليل النص باستخدام التحليل اللغوي - بما فيه من الأشكال الرسمية مثل المفردات والنحو والبنية النصوصية - والتحليل بين النصوص (intertextual). يعد التحليل بين النصوص جزءًا مهمًا من وجهة نظر فاركلوف، حيث يرى بأن النص هو متأصل في وحدة بين النصوص. والتناص (intertextuality) له شكل عمودي وشكل عرضي تواصلان يربط صانع النص بمستلم النص وين ويربط وفيط أيضا النص بعضه البعض (Noverino 2015, 110). إذا كان التحلي التحليل بين فين النصوص لفت الانتباه إلى اعتماد النص على المجتمع والتاريخ في شكل موارد

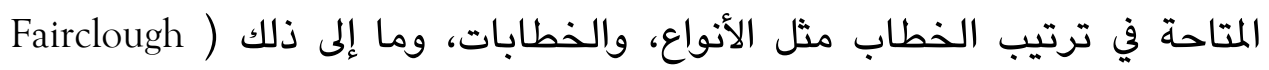

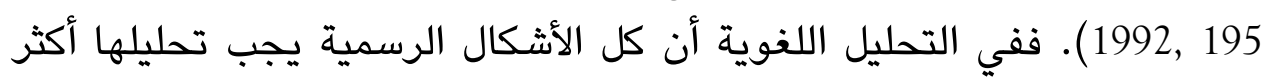

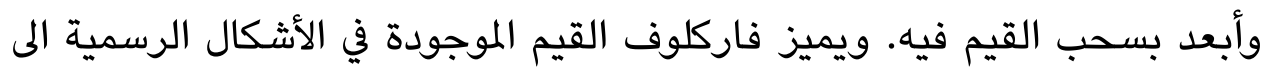

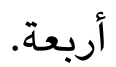

ا. القيمة التجريبية هي بالإشارة الى الأثر الأيديولوجي المستخدمة من قبل

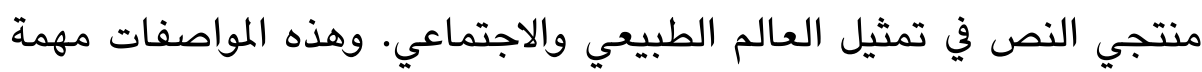
للكثف عن مدى الاختلافات الأيديولوجية تؤثر بشكل كبير على استخدام الألفاظ والكلمات في النص. ففي الجانب النحوي، ترتبط القيمة التجريبية

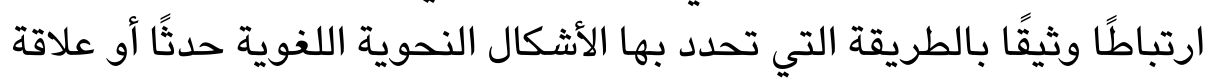

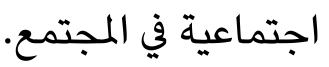

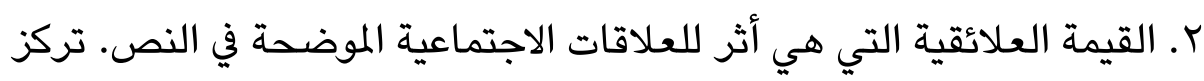

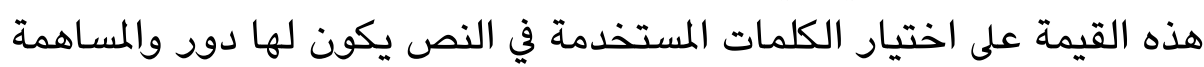


في الكشف عن العلاقة بين المشاركين. وفي الجوانب النحوية يمكن رؤية القيمة العلائقية في الأشكال النحوية المختلفة المستخدمة حيث يكون الشكل المئ النحوي المعين له آثارًا وانعكاسات معنوية مختلفة. وغير استخدام الأشكال النحوية

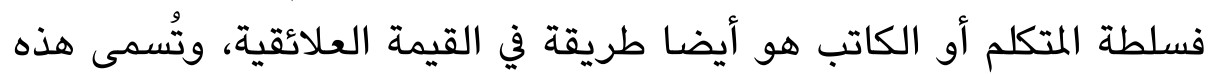
الطريقة كالطريقة التعبيرية التي تشير إلى إختبار حقيقة المتكلم أوالكاتب.

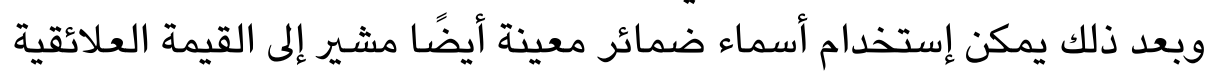
التي يريد أن ينقلها في النص. r. القيمة التعبيرية التي هي درب تقييم منتج النص للواقع ذي دي صلة. وفي

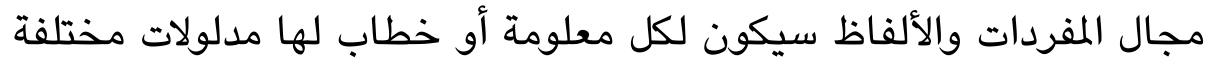

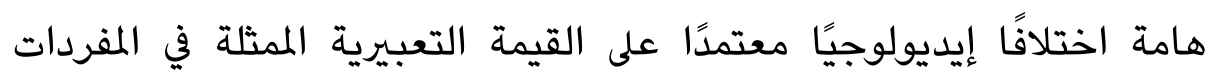
والألفاظ المستخدمة. ع. القيمة الرابطية التي تريط أجزاء من النص، وبالإضافة إلى ريط الأجزاء

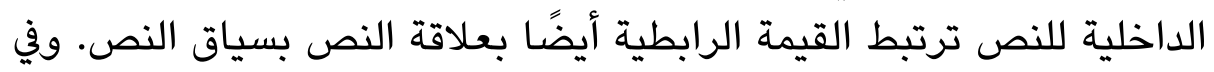

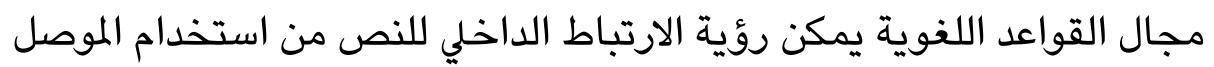
(حرف عطف) والمرجع (الجملة المشار إليها بجملة بعد ذلك) والتماسك بين

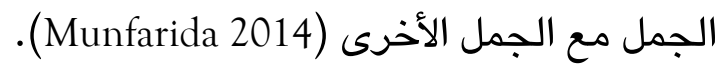

وقبل تفسير النص من الضروري أولاً تفسير سياق النص، والمقصود (لفرد

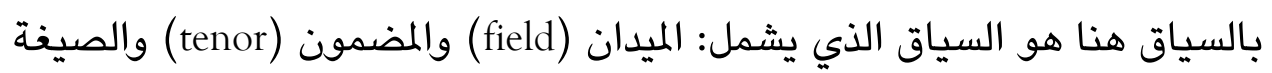
(mode) المستمر. والمضمون هو علائقي يشير إلى من يشـارك في النص ولمن يقصد النص في النص

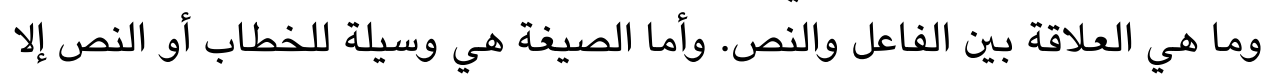

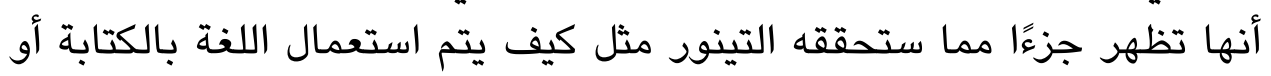
النطق كعمل أو تأمل (Ellyawati 2016).

مثال على ذلك هو عبارة مثيرة للجدل أن "الدين هو العدو الأكبر لبانجاسيلا (Pancasila)" وإذا نظرنا إلى باراديم التناقض فمن المستحيل أن يكون بانجاسيلا المولود من بينها من القيم الدينية مخالفا للدين نفسه ولذلك يكون بارئ 
تحليل تلك العبارة أو الخطاب ضروري. وعند إجراء تحليل ذلك الخطاب يجب دراسة النص كجزء من الخطاب، ولكن قبل ذلك لا بد من تحليل الصورة السياقية

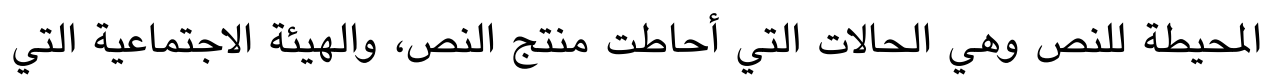

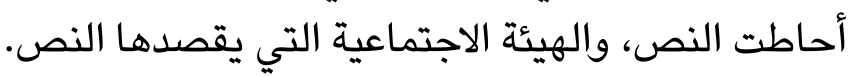

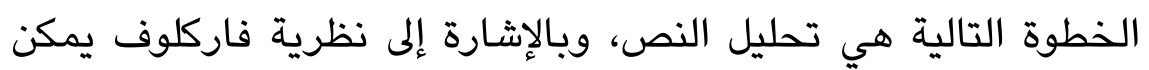

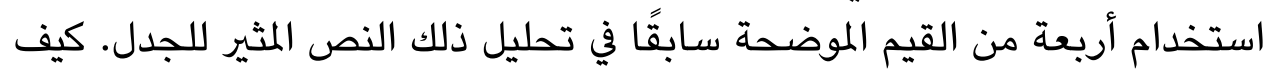
تمثل القيمة التجريبية ببساطة في النص الأثر الأيديولوجي الذي يؤثر على دئ إنتاج

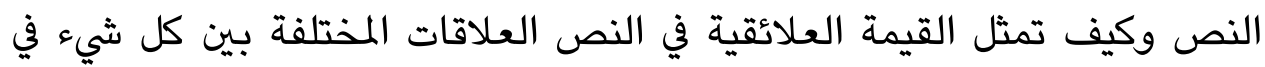
النص وكيف تعبر القيمة التعبيرية للنص عن تقييم منتج النص للواقع المحيط

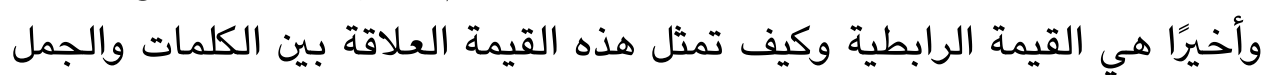
وكذلك العلاقة بين النص والسياق المحيط به أي ما يسمى أيضاً بأسباب الورود. وأما في النظر إلى العلاقة بين النص والسياق السيط فعلى الهي سبيل المثال يرى د. د.

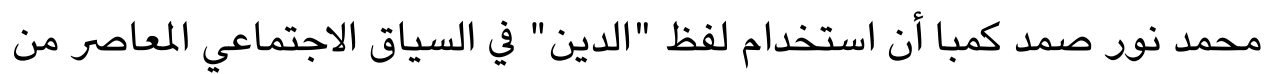
التقاليد الشفهية والكتابتية رجع إلى المعاني المختلفة منها: (1) التعاليم الدينية،

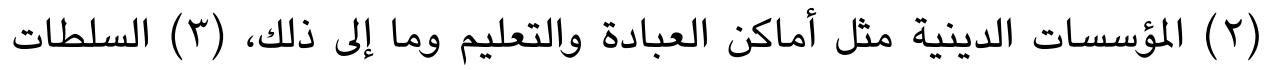

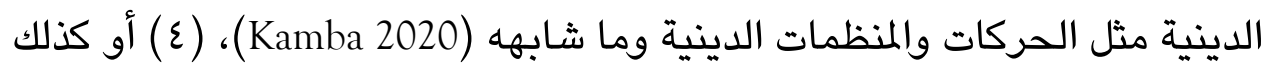
التفاسير والتأويلات للنصوص الدينية. إن تفصيل هذه الأنواع من المعاني - كما تستخدم في نقد المتن - إذا طبقناه في عملية تحليل المعلومات، سيكون مفيدًا جدًا في محاولة التحقق من صحة المعلومات كلما ظهرت. فلذلك ليس من السهل الوقوع في التحيز في المعلومات، ولا سيما في المعلومات الاستفزازية عن قصد أو أو حتى المعلومات الوهمية الكاذبة.

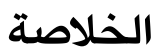

هذا هو البيان عن المنهجية التي استخدمها علماء الحديث في نقد متن الحديث. والبيانات حول هذه المنهجية في نقد متن الحديث مهمة للتوضيح كواحد من الوسطاء لفهم الباراديم المستخدم من قبل علماء الحديث في النقد على المتن. 
ومن البيان السابق يمكن الاستتتاج والاستنباط أن الباراديم الذي استخدمه علماء

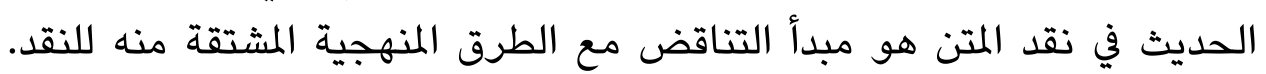
والباراديم والطرق المنهجية المستخدمة عند علماء الحديث لا يزال ملائق وملائم حتى اليوم. وأما تحول نقد متن الحديث في العصر الحديث نوعان، داخلي

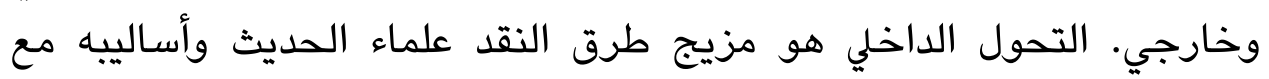

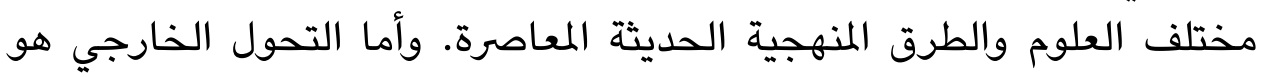

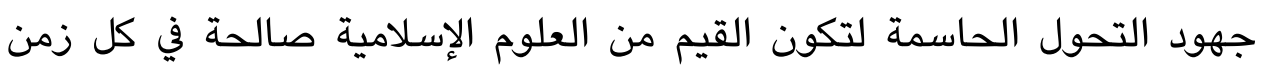
ومكان. وأخيراً فمع كل قدرة المؤلف المحدودة يكون هذا البحث والدراسة بعيدا من الكمال، ولذلك يأمل الباحث الكاتب على ردود الفعل والنقد والاقتراحات.

\section{References}

al-Adlabî, Shalâh al-Dîn ibn Aḥmad. 1983. Manhaj Naqd al-Matn 'inda 'Ulamâ' al-Hadîth al-Nabawî. Beirut: Dâr al-Afâq al-Jadîd.

Amrullah, Amrullah. 2016. "Eksistensi Kritik Matan Masa Awal: Membaca Temuan dan Kontribusi Jonathan Brown.” Kontemplasi: Jurnal IlmuIlmu Ushuluddin 4(1): 1-26.

DOI: http://dx.doi.org/10.21274/kontem.2016.4.1.1-26

Ayub, Ayub. 2018. "Matn Criticism and Its Role in the Evaluation of Hadith Authenticity." IJISH: International Journal of Islamic Studies and Humanities 1(1): 69-75.

DOI: https://doi.org/10.26555/ijish.v1i1.136

al-Baghdâdî, Abû Bakr Aḥmad ibn 'Alî ibn Thâbit al-Khațîb. 2012. alKifâyah fì 'Ilm al-Riwâyah. Beirut: Dâr al-Kutub al-'Ilmiyah.

Brown, Jonathan A.C. 2008. "How We Know Early Hadith Critics Did Matn Criticism and Why It's so Hard to Find." Islamic Law and Society 15(2): 143-84.

DOI: https://doi.org/10.1163/156851908X290574

Brown, Jonathan A.C. 2012. "The Rules of Matn Criticism: There Are No Rules." Islamic Law and Society 19(4): 356-96.

DOI: https://doi.org/10.1163/156851912X639923 
Ellyawati, Hetty Catur. 2016. "Analisis Wacana Kritis Teks Berita Kasus Terbongkarnya Perlakuan Terhadap Terpidana Suap Arthalyta Suryani Pada Media Online." Jurnal The Messenger 3(2): 19-35.

DOI: http://dx.doi.org/10.26623/themessenger.v3i2.267

Fairclough, Norman. 1992. "Discourse and Text: Linguistic and Intertextual Analysis within Discourse Analysis." Discourse E Society Journal 3(2): 193-217.

DOI: https://doi.org/10.1177/0957926592003002004

Ismail, M. Syuhudi. 2016. Metodologi Penelitian Hadis Nabi. Jakarta: Bulan Bintang.

'Itr, Nûr al-Dîn. 1979. Manhaj al-Naqd fî 'Ulûm al-Hadîth. Damascus: Dâr alFikr.

al-Jawâbî, Muhammad Tâhir. 1991. Juhûd al-Muhaddithîn fî Naqd Matn alHadîth al-Nabawî al-Sharîf. Tunisia: Mu'assasât Karîm ibn 'Abd Allâh.

Kamba, Muhammad Nursamad. 2020. Accessed March 6, 2020 15:38 WIB. https://twitter.com/mnkamba/status/1227604283006210049?s=08

Karcic, Fikret. 2006. "Textual Analysis in Islamic Studies: A Short Historical and Comparative Survey." Islamic Studies 45(2): 191-220.

Khalaf, Najm 'Abd al-Raḥmân. 1989. Naqd al-Matn bayna Șinâ'at alMuhaddithîn wa Matấ in al-Mustashriqîn. Riyad: Maktabah al-Rushd.

Muhsin, Masrukhin. 2017. "Kritik Matan Hadis Studi Komparatif antara Sarjana Muslim dan Sarjana Barat." AlQalam: Jurnal Kajian Keislaman 34(1): 167-202.

DOI: http://dx.doi.org/10.32678/alqalam.v34i1.1946

Mujibatun, Siti. 2014. "Paradigma Ulama Dalam Menentukan Kualitas Hadis dan Implikasinya Dalam Kehidupan Umat Islam." Analisis: Jurnal Studi Keislaman 14(1): 201-38.

DOI: https://doi.org/10.24042/ajsk.v14i1.655

Munfarida, Elya. 2014. "Analisis Wacana Kritis Dalam Perspektif Norman Fairclough.” Komunika: Jurnal Dakwah dan Komunikasi 8(1): 1-19.

DOI: https://doi.org/10.24090/KOMUNIKA.V8I1.746 
al-Nawawî, Muhy al-Dîn Abû Zakariyâ. 2001. Șahîh Muslim bi Sharh alNawawî. Cairo: Dâr al-Hadîth

Noverino, Romel. 2015. "Kajian Analisis Wacana Kritis Intertekstualitas (Interdiskursivitas) Pada Terjemahan yang Menggunakan Bahasa Gaul.” Proceeding PESAT (Psikologi, Ekonomi, Sastra, Arsitektur $\mathcal{E}$ Teknik Sipil): Jurnal Universitas Gunadarma 6: 108-16.

al-Ṣalâh, Abû Amr ibn. 1986. 'Ulûm al-Hadîth. Damascus: Dâr al-Fikr.

Suryadi, Suryadi. 2015. "Rekonstruksi Kritik Sanad dan Matan dalam Studi Hadis.” Esensia: Jurnal Ilmu-Ilmu Ushuluddin 16(2): 177-86.

DOI: https://doi.org/10.14421/esensia.v16i2.996

al-Suyûț̂i, Jalâl al-Dîn 'Abd al-Raḥmân ibn Abû Bakr. 1988. Tadrîb al-Râwî fî Sharh Taqrîb al-Nawawî. Beirut: Dâr al-Fikr.

al-Ṭaḥhân, Maḥmûd. 1996. Taysir Muștalah al-Hạith. Riyad: Maktabah alMa'ârif.

Tangngareng, Tasmin. 2016. "Methodology of Hadith Content Criticism: A Study of the Thought of Salah al-Din bin Ahmad al-Adlabi", Esensia: Jurnal Ilmu-Ilmu Ushuluddin 17(1): 97-110.

DOI: https://doi.org/10.14421/esensia.v17i1.1281 